\title{
The Case of the New Tagus River Leziria Bridge
}

\author{
Pedro Sêco e Pinto ${ }^{1}$, Ricardo Oliveira ${ }^{2}$, Alexandre Portugal ${ }^{3}$ \\ COBA Engineering and Environmental Consultants, Lisboa, Portugal \\ E-mail:pinto.pss@gmail.com (corresponding author)
}

\begin{abstract}
A brief description of the New Tagus River Leziria Bridge composed by $1695 \mathrm{~m}$ North Viaduct, by $970 \mathrm{~m}$ Main Bridge and by South Viaduct with a length of $9200 \mathrm{~m}$ is presented.

The observed thickness of the foundation alluvia material varies between $35 \mathrm{~m}$ and $55 \mathrm{~m}$ with a maximum value of $62 \mathrm{~m}$.

Hundred eighteen boreholes were performed with a depth between $21 \mathrm{~m}$ and $71 \mathrm{~m}$ and eight boreholes were performed from a maritime platform. Standard penetration tests (SPT) were carried out in all boreholes $1.5 \mathrm{~m}$ apart. In addition CPTu tests, seismic cone tests, crosshole and downhole tests were performed.

In three boreholes continuous undisturbed sampling with a triple sampler Geogor S was performed.

Related with static laboratory tests namely identification tests, triaxial tests, direct shear tests and oedometer tests were performed. In addition for the dynamic characterization reasonant columns tests and torsional cyclic tests were performed.

One of the most important considerations for the designers is the risk of earthquakes since Lisbon was wiped out by an 8.5 Ritcher magnitude earthquake in 1755. The seismic studies related to the design spectra were performed.

The liquefaction potential evaluation was performed only by field tests taking into account the disturbance that occurs during sampling of sandy materials. In this analysis attention was drawn for SPT and CPT tests as seismic tests have only been used when soil contains gravel particles. The shear stress values were computed from a total stresses model, that gave results on the conservative side using the code "SHAKE 2000".

For the North and South Viaducts $1.5 \mathrm{~m}$ diameter piles were used and for the Main Bridge $2.2 \mathrm{~m}$ diameter piles were used.

For the construction of the piles metallic casings were driven by a vibrofonceur or a hydraulic hammer and the piles length varies between $20 \mathrm{~m}$ to $56 \mathrm{~m}$.

Static pile load tests (both vertical and horizontal tests) were carried out on trial piles.

In addition pile dynamic tests were performed.

The construction aspects related with piles and bridge construction are addressed.

To assess the integrity of the piles reception tests by sonic diagraphies (crosshole tests) were performed.

Some problems that have occurred during piles construction in the Main Bridge, due to the gravel and cobbles dimensions, are described.

The bridge was monitored with the purposes of: (i) Validation of design criteria and calibration of mental model; (ii) Analysis of bridge behavior during his life; and (iii) Corrective measures for the rehabilitation of the structure.
\end{abstract}

Keywords: bridges, foundations, fiel and laboratory tests, seismic studies, liquefaction, construction aspects, pile tests, monitoring.

Conference topic: Soil and rock investigation.

\section{Introduction}

This paper is divided into four parts. In the first part a brief description of the New Tagus River Leziria Bridge is presented.

In the second part the main geological conditions are described. The field and laboratory tests are referred.

In the third part the analyses to derive the design free field surface spectra are described. The liquefaction potential assessment is performed.

The results of pile load tests carried out on trial piles are described.

The fourth part presents the construction issues, reception tests for piles, the characterization of gravel and cobbles materials, pile deteriorations and the objectives of monitoring during the construction phase and the long term.

Some final considerations are presented.

\section{Part 1}

\author{
"If wishes would prevail with me \\ my purpose should not fail with me" \\ Shakespeare, King Henry V.
}

\section{Brief description of the bridge}

The Project related with the Conception, Design, and Construction of Tejo Crossing in Carregado "(Sublanço A1/Benavente da A10 Auto-Estrada Bucelas/Carregado/ IC3)" was awarded by BRISA to a Construction Consortium composed by the following companies: Moniz da Maia, Serra \& Fortunato-Empreiteiros, S.A., Bento Pedroso Construções, S.A. Construtora do Tâmega, S.A., Lena Engineering and Construction, S.A., Novopca-Construction Associates, S.A and Zagope -Constructions and Engineering, S.A. 
This Consortium has awarded the Conception and Design to a Group composed by the companies COBA, PC\&A, CIVILSER and ARCADIS.

The crossing (Fig. 1) that integrates the North Viaduct, the Main Bridge and the South Viaduct is subsequently described (GRID 2003).

The Basic Design of this $11.9 \mathrm{~km}$ long crossing of the Tagus river, located $25 \mathrm{~km}$ upstream of the Vasco da Gama Bridge was carried out in 2004. The schedule for the design and construction was 21 months.

The river, $1 \mathrm{~km}$ wide, runs in an alluvial plain corresponding to the Tagus valley, filled with soft sediments.

The $1695 \mathrm{~m}$ North Viaduct has $33 \mathrm{~m}$ spans. The deck is a concrete $2.0 \mathrm{~m}$ depth beam directed connected to $1.5 \mathrm{~m}$ diameter piers. There is a $62 \mathrm{~m}$ span to cross the railway (Fig. 2).

The deck is $23 \mathrm{~m}$ above the water level (COBA, PC\&A, CIVILSER e ARCADIS 2004a).

The cross-section of the Main Bridge is composed by (COBA, PC\&A, CIVILSER e ARCADIS 2004b, 2005d; Portugal et al. 2005):

- a $0.30 \mathrm{~m}$ width reserve;

- interior hard shoulder;

-3 traffic lanes, each with $3.50 \mathrm{~m}$ with a total width of $10.50 \mathrm{~m}$;

$-2.525 \mathrm{~m}$ exterior hard-shoulder.

The platform includes a kerb on which rests a safety barrier, a maintenance footwalk and a edge beam with a total width of $1.15 \mathrm{~m}$.

The total width of the platform is $29.95 \mathrm{~m}$.

The deck is made of a pre-stressed cast in place concrete box-section $970 \mathrm{~m}$ long (Fig. 3). The individual spans are: $95+6 \times 130+95 \mathrm{~m}$. Piers P1 to P5 are monolitical with the deck and composed by two blades of reinforced concrete with $1.20 \mathrm{~m}$ thick spaced
$5.0 \mathrm{~m}$ between axes. Piers P6 to P7 are similar with the blades spaced $7.40 \mathrm{~m}$.

The thickness of alluvia materials is between $35 \mathrm{~m}$ and $55 \mathrm{~m}$, with a maximum value of $62 \mathrm{~m}$ (Oliveira et al. 2008).

The foundations are composed by $2.20 \mathrm{~m}$ diameter piles. The Piers P3 to P7 and the Piers P1 and P2 are supported by 8 piles and 10 piles, respectively. The piles were built by metallic casings $17 \mathrm{~mm}$ thick driven to the Miocene formations between $1 \mathrm{~m}$ and $5.5 \mathrm{~m}$ depending of the gravel materials thickness.

The sacrificial thickness of the casings varies between $7.2 \mathrm{~mm}$ and $5 \mathrm{~mm}$ to face corrosion.

The pile caps with $11.0 \times 22.0 \mathrm{~m}$ and $8 \mathrm{~m}$ thick to support piers P1C and P2C, were designed to resist ship impact. Pile cap with $11.0 \times 16.0 \mathrm{~m}$ and $5.05 \mathrm{~m}$ thick supports piers $\mathrm{P} 3 \mathrm{C}$ to $\mathrm{P} 7 \mathrm{C}$.

The South Viaduct integrates a set of 22 continuous viaducts with a total length of $9230 \mathrm{~m}$ with a concrete deck longitudinal prestressed with current spans of $36 \mathrm{~m}$ and $1.5 \mathrm{~m}$ of diameter piles.

One of the most important considerations for designers is the risk of earthquakes since Lisbon was wiped out by an 8.5 Ritcher magnitude earthquake in 1755. In the event of serious seismicity activity the new Tagus bridge will be one of the main access for emergency vehicles crossing the estuary.

\section{Part 2}

"Errors like straw, upon the surface blow.

He who search for pearls must dive below". John Dryden

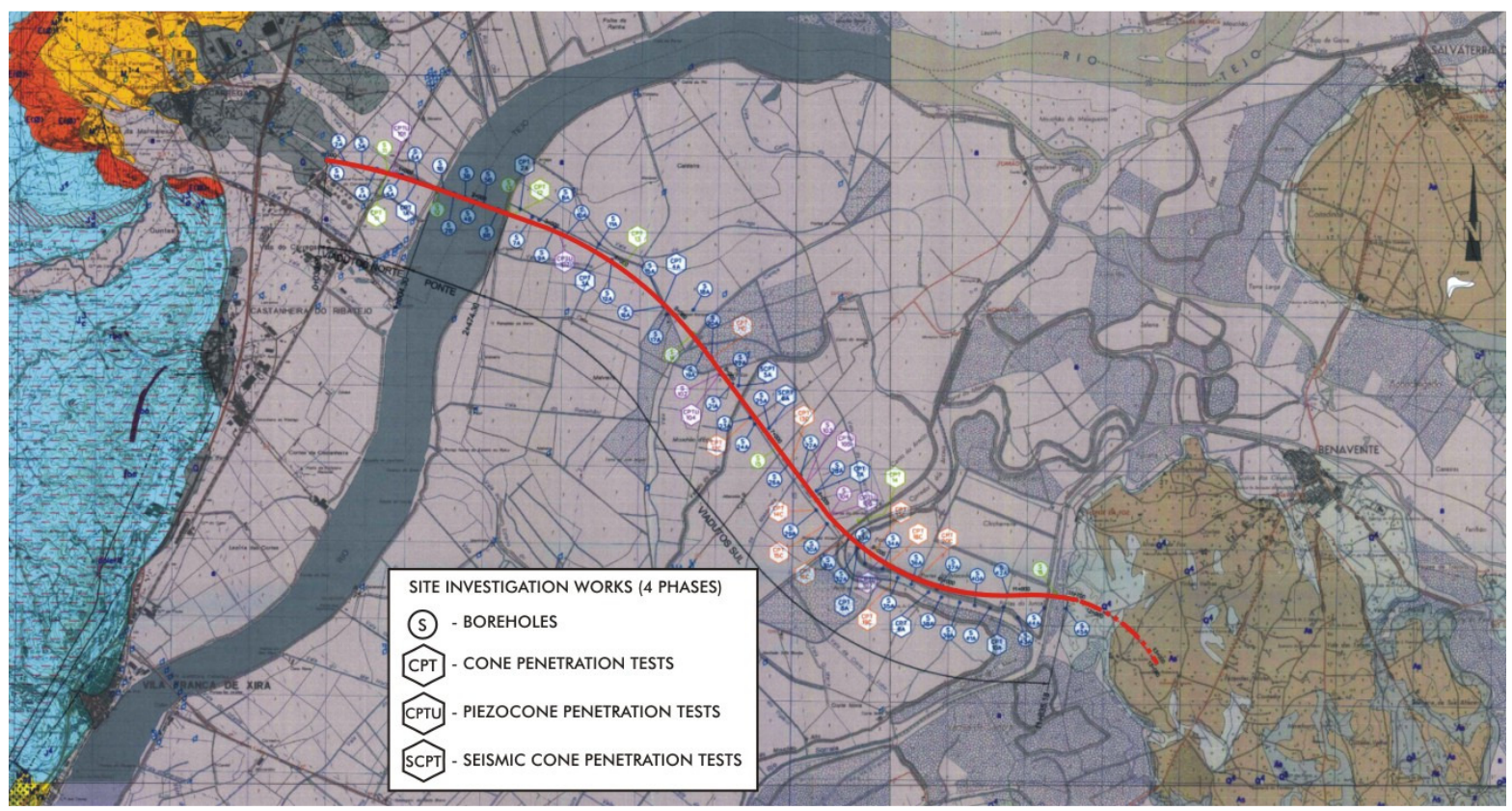

Fig. 1. Leziria Tagus River Crossing site 


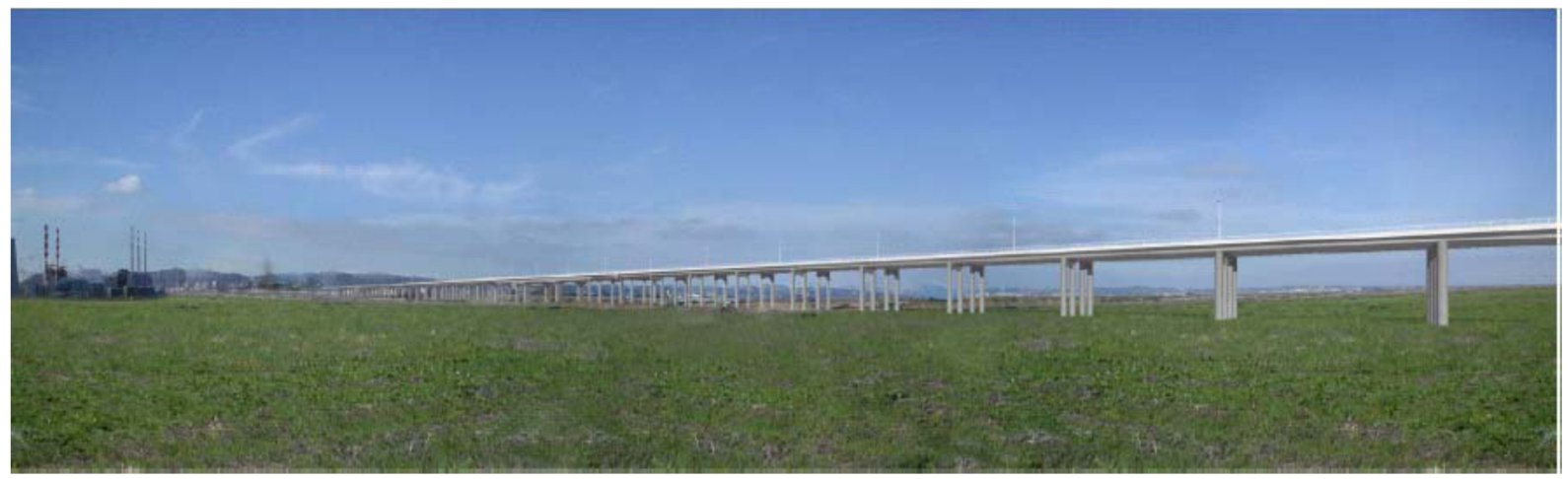

Fig. 2. North Viaduct (courtesy of Charles Lavigne)

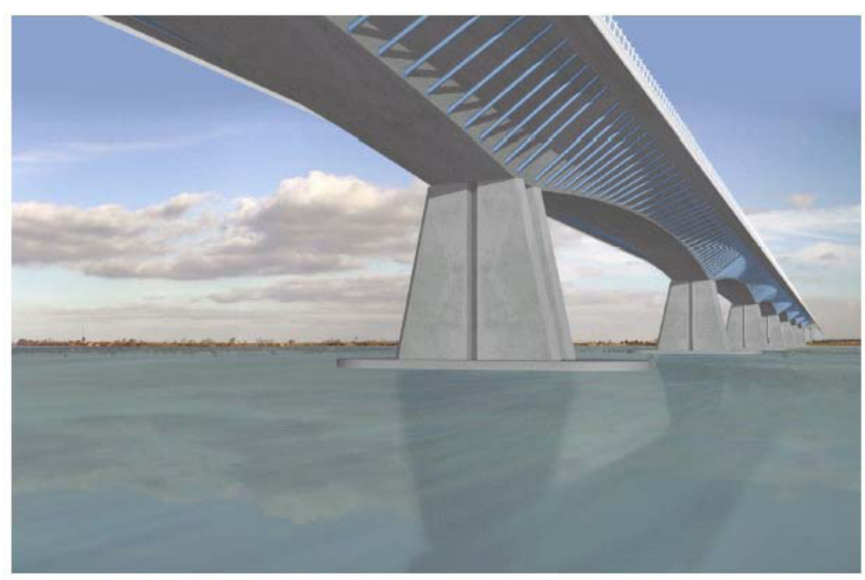

Fig. 3. Main Bridge (courtesy of Charles Lavigne)

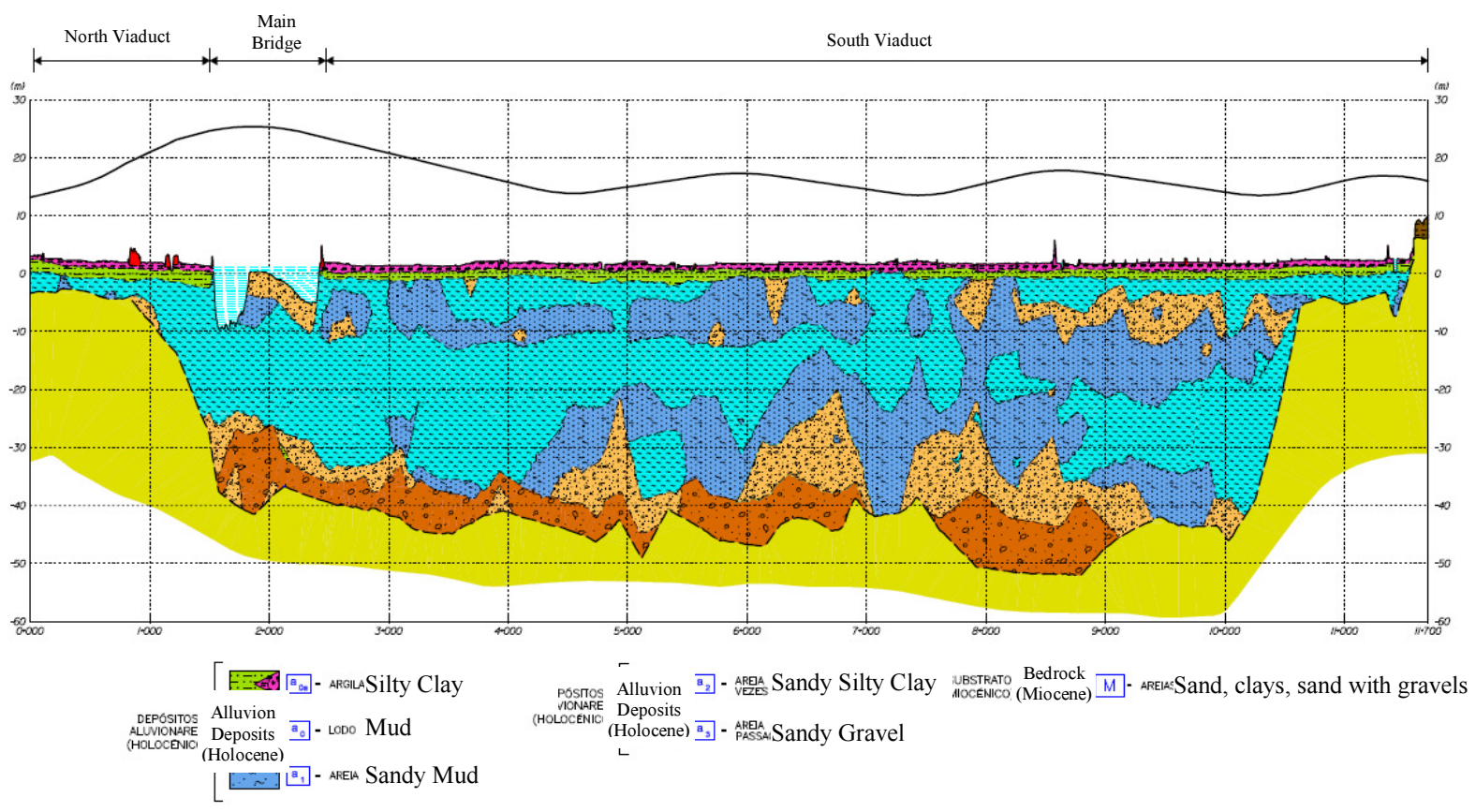

Fig. 4. Simplified geological profile 


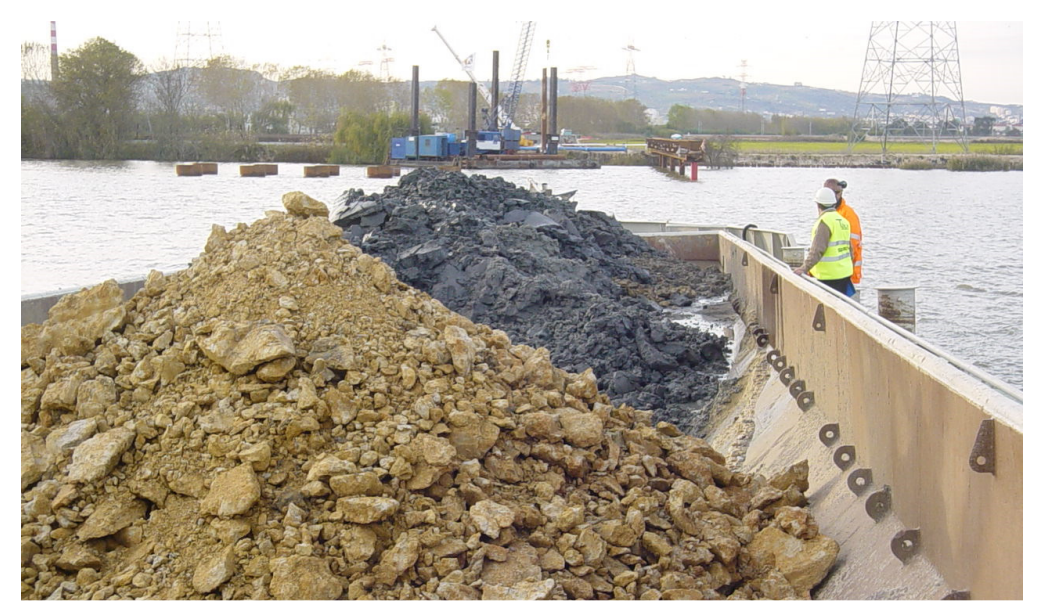

Fig. 5. Visual aspect of the materials

\section{Main geological conditions}

Regional geology

The new Tagus River crossing is located in the Cenozoic basin of the Tagus river and is composed by sedimentary materials of Miocene and Paleocene ages.

A simplified geological profile is presented in Figure 4 (COBA, PC\&A, CIVILSER e ARCADIS 2004e).

\section{Geomorphology}

The morphology is flat located at levels of 4 to $5 \mathrm{~m}$, and crossed by secondary water streams, protection dykes and water channels.

\section{Geological structure}

The tertiary formations, at regional scale, exhibit horizontal stratification with weak deformation.

\section{Litostratigraphy}

The site is composed by recent superficial deposits, namely Holocene alluvial and quaternary fluvial terraces above the bedrock composed by Miocene claygrey materials.

The visual aspects of materials are shown in Figure 5.

\section{Hydrogeological conditions}

The superficial layers with characteristics of free aquifer exhibit phreatic water level near the surface. The alluvial formations show characteristics for the occurrence of suspended, closed or half closed aquifers.

The Miocene formations exhibit favorable conditions for the occurrence of closed aquifers or semi closed aquifers with artesianism.

\section{Field investigation}

The field investigations have included 58 boreholes, namely 6 boreholes during the 1st stage of the Preliminary Studies, 49 boreholes in the 2nd stage and 3 boreholes during the complementary investigation program for the Basic Design. The boreholes were performed by Geocontrole (2004a).

In all boreholes the disturbed samples collected by Terzaghi sampler were classified, the water level was recorded and SPT tests, $1.5 \mathrm{~m}$ apart, were performed.

In addition 32 undisturbed samples were collected using Shelbi and Proctor-Moran samplers.

Thirty two cone penetration tests, namely $4 \mathrm{CPT}$ tests during the $1^{\text {st }}$ stage of Preliminary Studies, $20 \mathrm{CPT}$ tests during the $2^{\text {nd }}$ stage, $6 \mathrm{CPTu}$ tests using electrical cone friction sleeve and porous ceramic filter stone located at the conical tip, and 2 seismic cones were performed (Geocontrole 2004a).

Nineteen vane shear tests, namely 3 tests during the first stage of the Preliminary Studies, 16 tests during the second stage (Geocontrole 2004a).

9 seismic crosshole tests were performed, namely 7 tests by GEOCISA (2003) and 2 tests by LNEC (2003) during the $2^{\text {nd }}$ phase of Preliminary Study. In addition 7 downhole tests were performed.

During the Final Design the complementary geotechnical project has integrated (Geocontrole 2004b, 2004c):

i) 41 boreholes with SPT tests $1.5 \mathrm{~m}$ apart (Fig. 6);

ii) 10 vane shear tests;

iii) 25 undisturbed samples taken with Geabor $\mathrm{S}$ sampler (Fig. 7);

iv) 16 CPTU tests (Figs 8 and 9);

v) 5 seismic crosshole tests.

A summary of field tests is presented in Table 1. results:

The crosshole tests have given the following

Shear wave velocities $\mathrm{V}_{\mathrm{s}}$ from 53 to $350 \mathrm{~m} / \mathrm{s}$

Longitudinal wave velocities $\mathrm{V}_{\mathrm{p}}$ from 665 to $1526 \mathrm{~m} / \mathrm{s}$. 


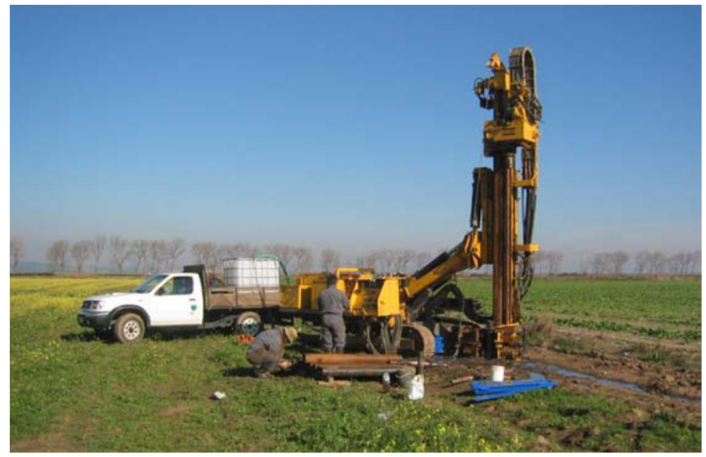

Fig. 6. Borehole equipment

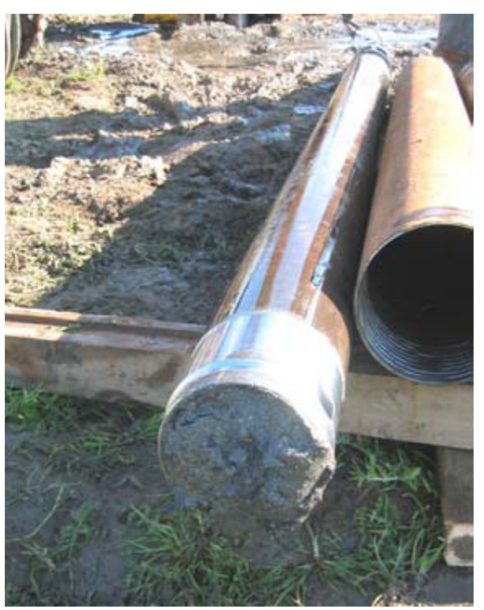

Fig. 7. Geobor S sampler

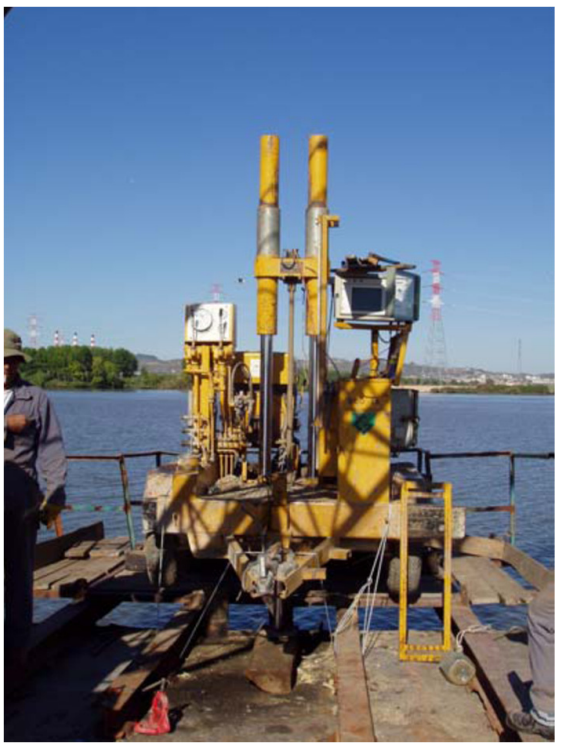

Fig. 8. CPTu equipment

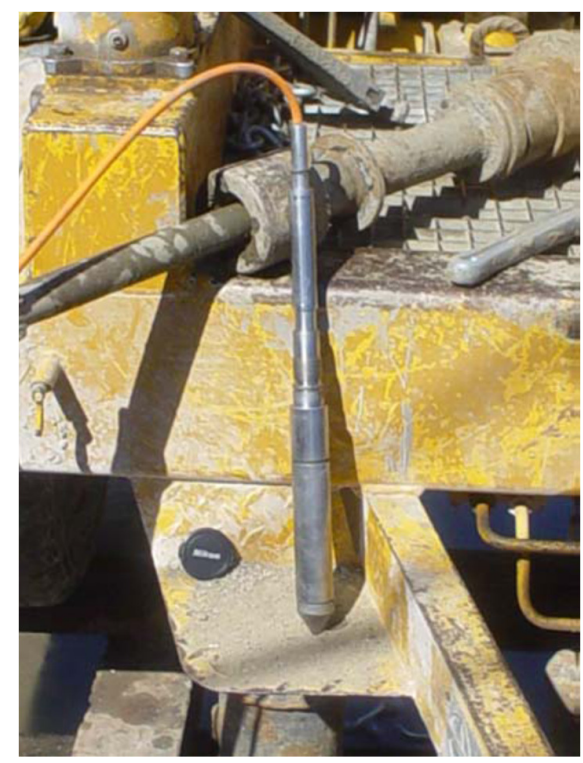

Fig. 9. CPTu tip

Vs $(\mathrm{m} / \mathrm{s})$

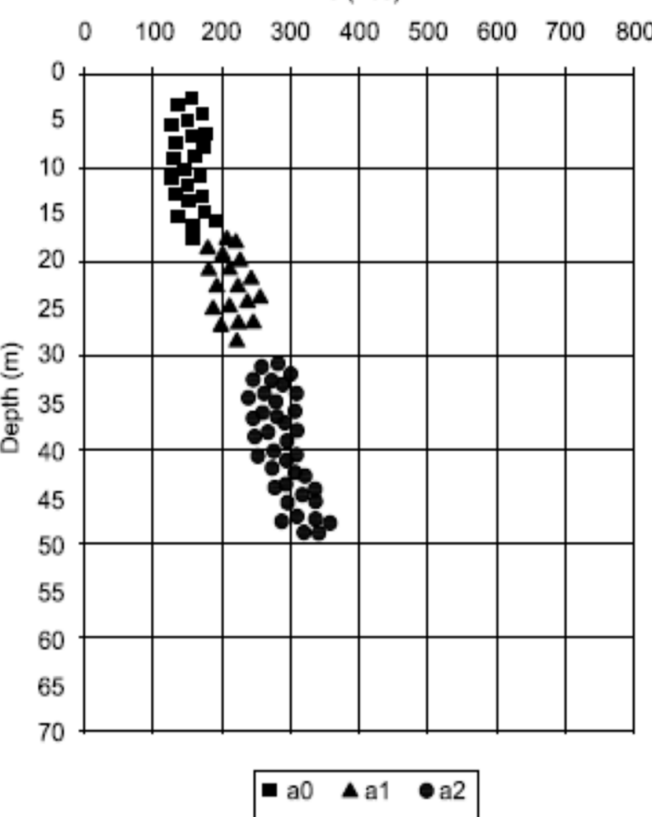

Fig. 10. Variation of $\mathrm{V}_{\mathrm{s}}$ with depth

The variation of $\mathrm{V}_{\mathrm{s}}$ with depth is shown in Figure 10.

SPT results were between 0 and 4 blows, with a large frequency of 0 values and the higher values related with silty materials.

Vane shear tests have given for undrained strength the following results:

peak values -12.5 to $51 \mathrm{kPa}$,

residual values -4 to $26.3 \mathrm{kPa}$.

The variation of these values is shown in Figure 11. 


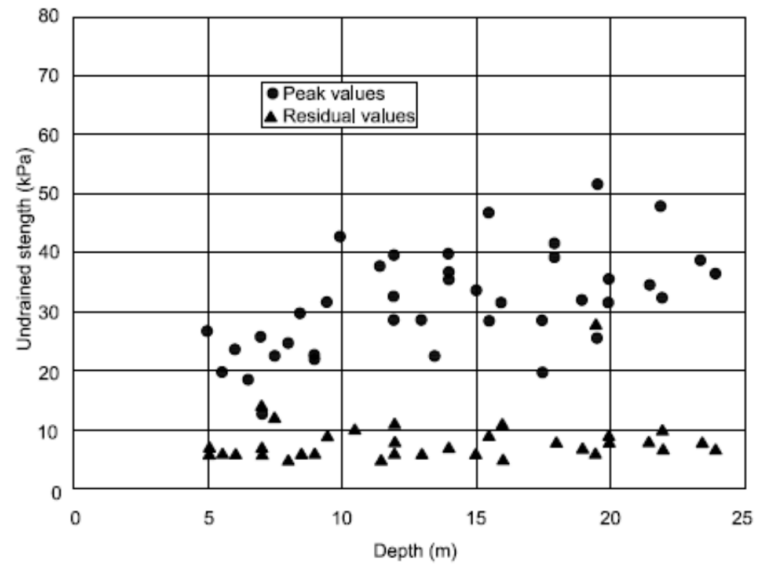

Fig. 11. Variation of undrained strengths with depth

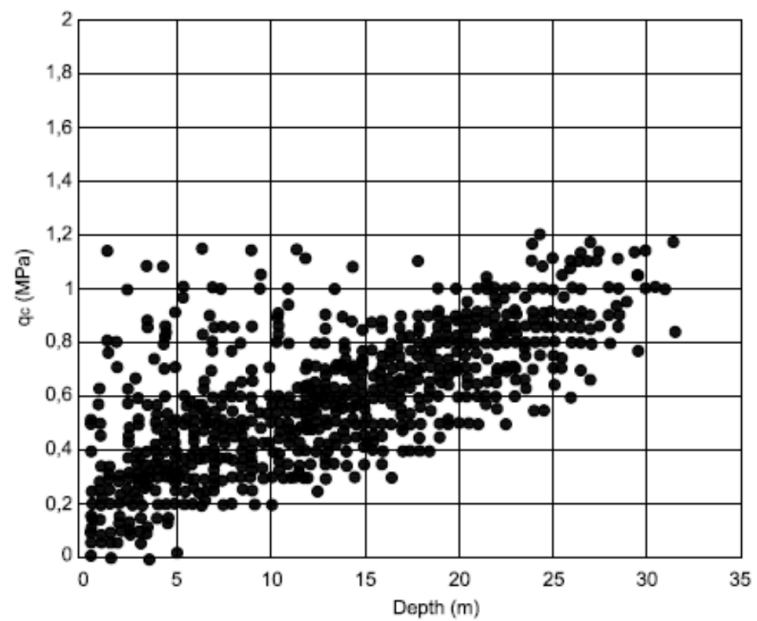

Fig. 12. Variation of $\mathrm{q}_{\mathrm{c}}$ values with depth

PCPT tests, with measurement of pore pressures, have given point resistances between 0.15 and $1.2 \mathrm{MPa}$, with an increase with depth. This trend is illustrated in Figure 12.

Pore pressures values have allowed the identifycation of material, higher values were related with mud materials.

\section{Laboratory tests}

During the Basic Design 12 identification tests (sieve analyses and Atterberg limits) were performed by COBA.

During the $2^{\text {nd }}$ stage of Preliminary Studies forty three identification tests, consisted on sieve analyses as well on determinations of liquid limit, $\mathrm{W}_{\mathrm{L}}$, and plastic limit, $W_{P}$, were performed. Determinations of natural water content, $\mathrm{W}_{\mathrm{n}}$, were also done.

A summary of laboratory tests is presented in Table 2 (Geocontrole 2004c).

In three water samples $\mathrm{PH}$ tests, determinations of alkalis, sulphates content, magnesium content and ammonia content were performed.

Twenty two oedometre tests with the determination of the values of water content $\left(\mathrm{W}_{\mathrm{n}}\right)$, degree of saturation $\left(\mathrm{S}_{\mathrm{r}}\right)$, pressures, compressibility volumetric coefficients $\left(a_{v}\right)$, consolidation coefficients $\left(c_{v}\right)$ and permeability coefficients $(\mathrm{k})$, were performed.

Six triaxial tests for the definition of the strength in terms of cohesion (c) and friction angle $(\phi)$ were done.

The curves $\left(\sigma_{1}-\sigma_{3}\right)$ versus axial strain $\left(\varepsilon_{1}\right), \sigma_{1} / \sigma_{3}$ versus $\varepsilon_{1}$, variation of pore pressure (u) versus $\varepsilon_{1}$, and volumetric variation versus $\varepsilon_{1}$, as well as the stress path and the Mohr-Coulomb envelopes were obtained.

Nineteen direct shear tests for the definition of the strength in terms of cohesion (c) and friction angle $(\phi)$, were performed.

Twenty-four permeability tests were done.

Twelve chemical tests related with sulphates content, carbonates content and $\mathrm{pH}$ values were performed.

Also twenty five particle density tests were performed.

Three cyclic torsional simple shear tests were done (IST 2005).

The curves $\mathrm{G}$ (shear modulus) versus $\gamma$ (shear strain), $\sqrt{G}$ versus $\gamma, \xi$ (damping ratio) versus $\gamma$ and $\gamma$ versus $\tau / \sigma o$ were obtained.

A view of cyclic torsional simple shear apparatus is presented in Figure 13.

The results of cyclic torsional tests are shown in Figure 14 (IST 2004b, 2005).

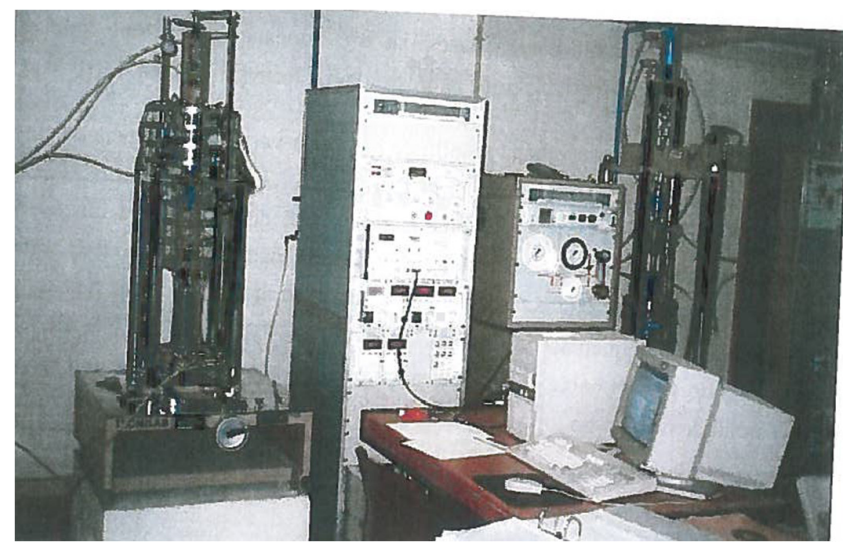

Fig. 13. View of cyclic torsional shear apparatus (after IST 2005) 
Table 1. Distribution of field tests

\begin{tabular}{l|c|c|c}
\hline \multicolumn{1}{c|}{ TESTS } & Basic Design & Final Design & TOTAL \\
\hline BOREHOLES & 58 & 60 & 118 \\
\hline BOREHOLES UNDISTURBED SAMPLING & 0 & 3 & 3 \\
\hline VANE SHEAR TESTS & 19 & 7 & 26 \\
\hline CROSSHOLE & 9 & 6 & 15 \\
\hline CPTu/CPT & 28 & 23 & 51 \\
\hline SEISMIC CONE & 2 & 4 & 6 \\
\hline
\end{tabular}

Table 2. Distribution of laboratory tests

\begin{tabular}{l|c|c|c}
\hline \multicolumn{1}{c|}{ TESTS } & Basic Design & Final Design & TOTAL \\
\hline IDENTIFICATION & 55 & 180 & 235 \\
\hline SIEVE CURVES & 55 & 180 & 235 \\
\hline OEDOMETRE & 4 & 18 & 22 \\
\hline TRIAXIAL & 0 & 6 & 6 \\
\hline DIRECT SHEAR & 6 & 13 & 19 \\
\hline PERMEABILITY & 6 & 18 & 24 \\
\hline CHEMICAL & 3 & 9 & 12 \\
\hline RESONANT COLUMN & 0 & 3 & 3 \\
\hline TORSIONAL SHEAR CYCLIC & 0 & 3 & 3 \\
\hline PARTICLE DENSITY & 3 & 22 & 25 \\
\hline
\end{tabular}
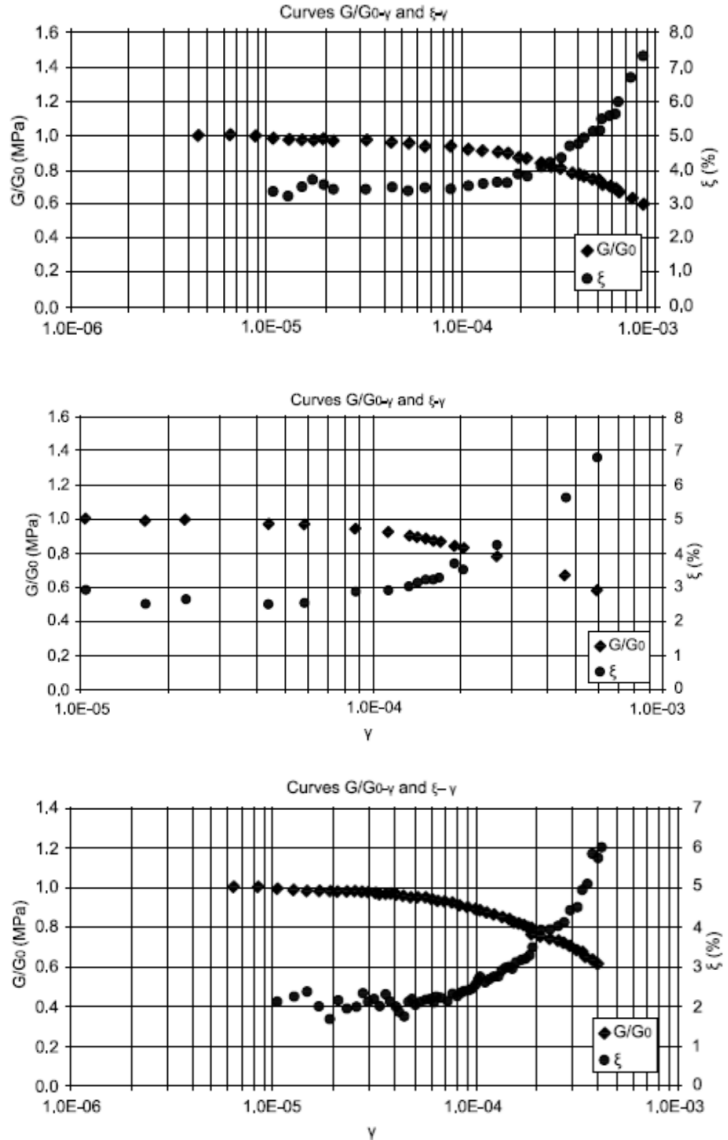

Fig. 14. Curves shear modulus and damping ratio versus shear strain (after IST 2005)

\section{Geotechnical characteristics}

Based in the interpretation of site investigation programme and laboratory and in situ tests the following geotechnical units were identified (COBA, PC\&A, CIVILSER e ARCADIS 2004c, 2004d; Oliveira et al. 2008):

- Geotechnical unit $\mathrm{a}_{0 \mathrm{a}}$;

- Geotechnical unit $a_{0}$;

- Geotechnical unit a1;

- Geotechnical unit a2;

- Geotechnical unit a3;

- Geotechnical unit M.

The description of each unit based in the geological and geotechnical characteristics will be presented.

\section{Geotechnical units}

Unit $\mathrm{a}_{0 a}$

Composed by grey silty clay.

Thickness from 2 to $3 \mathrm{~m}$.

Unified classification $\mathrm{CH}$.

AASHTO classification A-7-6.

\% passing sieve \# 200 (ASTM) 95 to $99 \%$.

Liquid limit 64\%.

Plastic limit 38\%.

Natural water content $31.5 \%$.

Density of particles $=1.86$.

The crosshole tests have given the following results:

Shear wave velocities $\mathrm{V}_{\mathrm{s}}$ from 130 to $160 \mathrm{~m} / \mathrm{s}$. 

$1526 \mathrm{~m} / \mathrm{s}$

Longitudinal wave velocities $\mathrm{V}_{\mathrm{p}}$ from 665 to

Edin $(\mathrm{MPa})$ values between 50 and 150 .

Gdin (MPa) values between 20 and 100 .

SPT results were between 2 and 6 blows.

PCPT tests, with measurement of pore pressures, have given point resistances between 1 and $2 \mathrm{MPa}$.

Vane shear tests have given for undrained strength the following results:

peak values -22 to $26 \mathrm{kPa}$;

residual values -7 to $8 \mathrm{kPa}$.

Cohesion (total stress) $\mathrm{c}=22 \mathrm{kPa}$.

Friction angle $\phi=30^{\circ}$.

Oedometre tests:

$\mathrm{a}_{\mathrm{v}}($ compressibility volumetric coefficient $)=$

0.172 to 0.6618 .

Void ratio 1.234 to 2.025 .

$\mathrm{c}_{\mathrm{v}}($ consolidation coefficient $)=$

$\mathrm{k}($ permeability coefficient $)=$

$$
2,1 \text { to } 28 \times 10^{-8} \mathrm{~m}^{2} / \mathrm{s} \text {. }
$$

0.34 to $1.8 \times 10^{-10} \mathrm{~m} / \mathrm{s}$.

Taken into account the results of the tests and correlations from the literature the following mechanical characteristics were adopted (COBA, PC\&A, CIVILSER e ARCADIS 2005e, 2005f, 2005g):

Unit weight $(\mathrm{kN} / \mathrm{m} 3)-18$.

Undrained cohesion (cu) $(\mathrm{kPa})-25$ to 30 .

Ks values $\left(\mathrm{kN} / \mathrm{m}^{3}\right)$

Piles $\Phi=1.5 \mathrm{~m}$ from 4000 to 8000 .

Piles $\Phi=2.0 \mathrm{~m}$ from 3000 to 4000 .

\section{Unit $a_{0}$}

Composed by mud material with intercalations of sandy material.

Thickness $=20 \mathrm{~m}$.

Unified classification OH-OL.

AASHTO classification A-7-6, A-7-5, A-4-(3), A4-(6).

$\%$ passing sieve \# 200 (ASTM) 94 to $100 \%$.

Liquid limit $29 \%$ to $78 \%$.

Plastic limit $27 \%$ to $50 \%$.

Natural water content $37.9 \%$ to $87.2 \%$.

Density of particles $=1.52$ to 2.16 . results:

The crosshole tests have given the following

Shear wave velocities $\mathrm{V}_{\mathrm{s}}$ from 120 to $170 \mathrm{~m} / \mathrm{s}$.

Longitudinal wave velocities $V_{p}$ from 665 to $1526 \mathrm{~m} / \mathrm{s}$.

Edin $(\mathrm{MPa})$ values between 50 and 150 .

Values of Gdin (MPa) between 20 and 100.

SPT results were between 2 and 6 blows.

PCPT tests, with measurement of pore pressures, have given point resistances between 0 and $2 \mathrm{MPa}$.
Vane shear tests have given for undrained strength the following results:

peak values -14 to $34 \mathrm{kPa}$.

residual values -6 to $13 \mathrm{kPa}$.

Cohesion (in total stress) $\mathrm{c}=3$ to $22 \mathrm{kPa}$.

Cohesion (in effective stresses $\mathrm{kPa}$ ) $\mathrm{c}=0$ to 12 .

Friction angle (in total stresses) $\phi=9$ to $31^{\circ}$.

Friction angle (in effective stresses) $\phi=13$ to $20^{\circ}$.

$\mathrm{a}_{\mathrm{v}}($ compressibility volumetric coefficient $)=0.172$ to 0.661 .

Void ratio 1.234 to 2.025 .

$\mathrm{c}_{\mathrm{v}}($ consolidation coefficient $)=$

$\mathrm{k}($ permeability coefficient $)=$ $2.3 \times 10^{-8}$ to $3.8 \times 10^{-7} \mathrm{~m}^{2} / \mathrm{s}$.

$$
1.6 \times 10^{-10} \text { to } 1.4 \times 10^{-9} \mathrm{~m} / \mathrm{s} \text {. }
$$

Taken into account the results of the tests and correlations from literature the following mechanical characteristics were adopted (COBA, PC\&A, CIVILSER e ARCADIS 2005e, 2005f, 2005g):

Unit weight $\left(\mathrm{kN} / \mathrm{m}^{3}\right)-16$.

Undrained cohesion (cu) $(\mathrm{kPa})-25-30$.

Ks values $\left(\mathrm{kN} / \mathrm{m}^{3}\right)$

Piles $\Phi=1.5 \mathrm{~m}$ from 1000 to 2000 .

Piles $\Phi=2.0 \mathrm{~m}$ from 750 to 1500 .

Unit a1

Composed by fine sandy materials with intercalations of silty clay material:

Thickness $=20 \mathrm{~m}$.

Unified classification SP, SP, SC.

AASHTO classification A-3-6, A-6-2, A-6-6.

$\%$ passing sieve \# 200 (ASTM) $6 \%$ to $42 \%$.

Liquid limit NP to $40 \%$.

Plastic limit NP to $18 \%$.

Natural water content $22.5 \%$ to $43.3 \%$.

Density of particles $=1.52$ to 2.16 . results:

The crosshole tests have given the following

Shear wave velocities $\mathrm{V}_{\mathrm{s}}$ from 130 to $240 \mathrm{~m} / \mathrm{s}$.

Longitudinal wave velocities $\mathrm{V}_{\mathrm{p}}$ from 665 to $1526 \mathrm{~m} / \mathrm{s}$.

Edin (MPa) values between 100 and 300 .

Valores de Gdin (MPa) values between 30 and 100 .

SPT results were between 2 and 20 blows.

PCPT tests, with measurement of pore pressures, have given point resistances between 2 and $8 \mathrm{MPa}$.

Cohesion (total stress) $\mathrm{c}=0 \mathrm{kPa}$.

Friction angle (in total stresses) $\phi=42^{\circ}$.

Taken into account the results of the tests and correlations from literature the following mechanical characteristics were adopted (COBA, PC\&A, CIVILSER e ARCADIS, 2005e, 2005f, 2005g):

Unit weight $(\mathrm{kN} / \mathrm{m} 3)-18.5$ to 19 .

Ks values $\left(\mathrm{kN} / \mathrm{m}^{3}\right)$

Piles $\Phi=1.5 \mathrm{~m}$ from 7000 to 30000 .

Piles $\Phi=2.0 \mathrm{~m}$ from 5000 to 22500 . 


\section{Unit a2}

Composed by fine sandy materials with intercalations of silty clay material with gravel material:

Thickness $=20 \mathrm{~m}$.

Unified classification SP, SM, SW.

AASHO classification A1-b, A-3-(0), A-2-4.

$\%$ passing sieve \# 200 (ASTM) $0 \%$ to $23 \%$.

Liquid limit NP.

Plastic limit NP.

Natural water content $22.3 \%$.

Density of particles $=1.52$ to 2.16 . results:

The crosshole tests have given the following

Shear wave velocities $V_{s}$ from 140 to $300 \mathrm{~m} / \mathrm{s}$.

Longitudinal wave velocities $\mathrm{V}_{\mathrm{p}}$ from 665 to $1526 \mathrm{~m} / \mathrm{s}$.

Edin $(\mathrm{MPa})$ values between 100 and 500 .

Values of Gdin (MPa) values between 20 and 200.

SPT results were between 5 and 40 blows.

PCPT tests, with measurement of pore pressures, have given point resistances between 3 and $16 \mathrm{MPa}$.

Cohesion (total stress) $\mathrm{c}=0 \mathrm{kPa}$.

Friction angle(in total stresses) $\phi=42^{\circ}$.

Taken into account the results of the tests and correlations from literature the following mechanical characteristics were adopted (COBA, PC\&A, CIVILSER e ARCADIS, 2005e, 2005f, 2005g):

Unit weight $\left(\mathrm{kN} / \mathrm{m}^{3}\right)-18.5$ to 19.5 .

Ks values $\left(\mathrm{kN} / \mathrm{m}^{3}\right)$

Piles $\Phi=1.5 \mathrm{~m}$ from 8000 to 55000 .

Piles $\Phi=2.0 \mathrm{~m}$ from 6000 to 41000 .

\section{Unit $a_{3}$}

Composed by medium sandy materials with intercalations of silty clay material with gravel material.

The thickness of this layer is variable.

Unified classification SP, SM,

AASHTO classification A-1-a.

$\%$ passing sieve \# 200 (ASTM) $0 \%$ to $6 \%$.

Liquid limit NP.

Plastic limit NP.

Natural water content $22.3 \%$.

Density of particles $=1.52$ to 2.16 .

The crosshole tests have given the following results:

Shear wave velocities $V_{s}$ from 320 to $400 \mathrm{~m} / \mathrm{s}$.

Longitudinal wave velocities $V_{p}$ from 665 to $1526 \mathrm{~m} / \mathrm{s}$.

Edin $(\mathrm{MPa})$ values between 500 and 1100 .

Values of Gdin (MPa) values between 200 and 400 .

SPT results were between 40 and 60 blows.

CPT tests, with measurement of pore pressures, have given point resistances between 3 and $16 \mathrm{MPa}$.

Taken into account the results of the tests and correlations from literature the following mechanical characteristics were adopted (COBA, PC\&A, CIVILSER e ARCADIS, 2005e, 2005f, 2005g):

Unit weight $(\mathrm{kN} / \mathrm{m} 3)-20.5$.

Ks values $\left(\mathrm{kN} / \mathrm{m}^{3}\right)$.

Piles $\Phi=1.5 \mathrm{~m}$ from 60000 to 90000 .

Piles $\Phi=2.0 \mathrm{~m}$ from 45000 to 68000 .

\section{Unit M}

The bedrock Miocene is composed of 4 units namely: $\mathrm{M}_{1}, \mathrm{M}_{2}, \mathrm{M}_{3}$ and $\mathrm{M}_{4}$.

Unit $M_{1}$ is composed by clays and sandy silty materials.

Unit M2 is composed by sands with intercalations of clay materials.

Unit M3 is composed by sands with intercalations of gravel materials.

Unit M4 is composed by sands with intercalations of gravel materials with sand silty. results:

The crosshole tests have given the following

Shear wave velocities $\mathrm{V}_{\mathrm{s}}$ from 400 to $500 \mathrm{~m} / \mathrm{s}$.

Edin (MPa) values between 500 and 1700 .

Values of Gdin (MPa) values between 200 and 600 .

SPT results were higher than 60 blows.

Taken into account the results of the tests and correlations from literature the following mechanical characteristics were adopted (COBA, PC\&A, CIVILSER e ARCADIS, 2004c):

Unit weight $(\mathrm{kN} / \mathrm{m} 3)-215$.

Ks values $\left(\mathrm{kN} / \mathrm{m}^{3}\right)$

Piles $\Phi=1.5 \mathrm{~m}$ from 90000 to 120000 .

Piles $\Phi=2.0 \mathrm{~m}$ from 68000 to 90000 .

A correlation between Vs and SPT values obtained by the tests with the proposal of some authors is shown in Figure 15.

Part 3

"A first rate theory predicts, a second rate theory forbids and a third rate theory explain after the event". A. I. Kitaigorowdswi, Russian Cientist, 1975.

\section{Design surface spectra}

\section{Introduction}

To derive the design free field surface spectra a very comprehensive analysis was performed.

\section{Seismic action}

The seismic action was based on the Portuguese Code (RSA 1983) and defined by a stochastic gaussian stationary vectorial process (two horizontal orthogonal components and one vertical component). The Portuguese territory is affected by two seismotectonic sources: (i) near source which represents a moderate magnitude earthquake at a short focal distance with a duration of 10 seconds; (ii) far source which represents 
a higher magnitude earthquake at a longer focal distance with a duration of 30 seconds.

For the deterministic approach five artificial time histories of acceleration were produced for seismic action type 1 and seismic action type 2 and for soil type A (IST 2004a). For the computation of these accelerograms the validation criteria of EC8 (1998a) was considered (Fig. 16).

For the stochastic approach power spectral density functions based on RSA (1983) were used.

Due to the length of the bridge of $12 \mathrm{Km}, 17$ geotechnical profiles were analyzed to incorporate the variation of the geological and geotechnical characteristics.

Due to space limitations only the results obtained for the profile located between $\mathrm{Km} 1+500$ and $\mathrm{Km} 1+800$ where the main bridge is located are presented.

In Figures 17 and 18 are presented the results of the response spectra (IST 2004a), as well as the shear stress obtained by the code SHAKE 2000. The analyses were performed for seismic action type 1 and seismic action type 2 considering in the bedrock a ground type A.

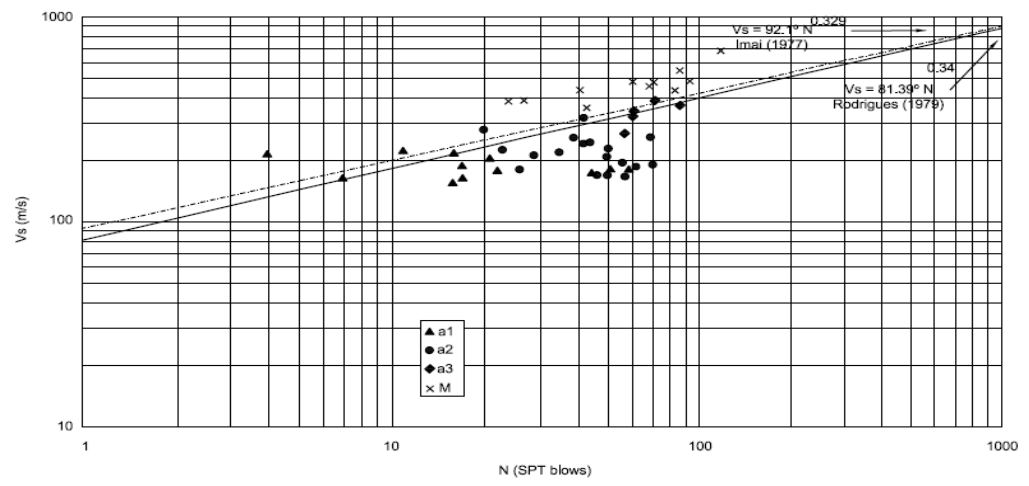

Fig. 15. A correlation between Vs and SPT values
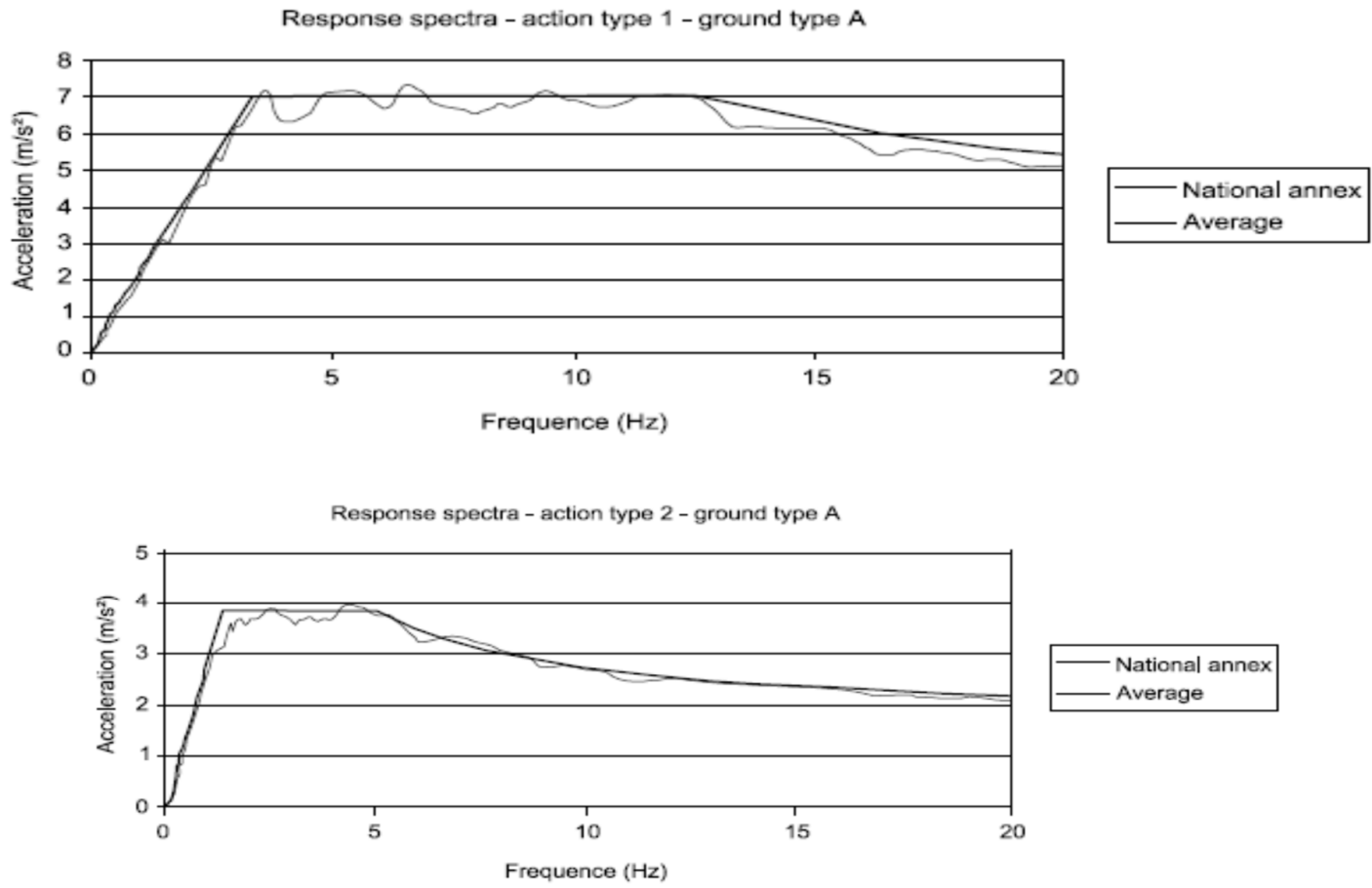

Fig. 16. Response spectra versus code spectra (after IST 2004a) 

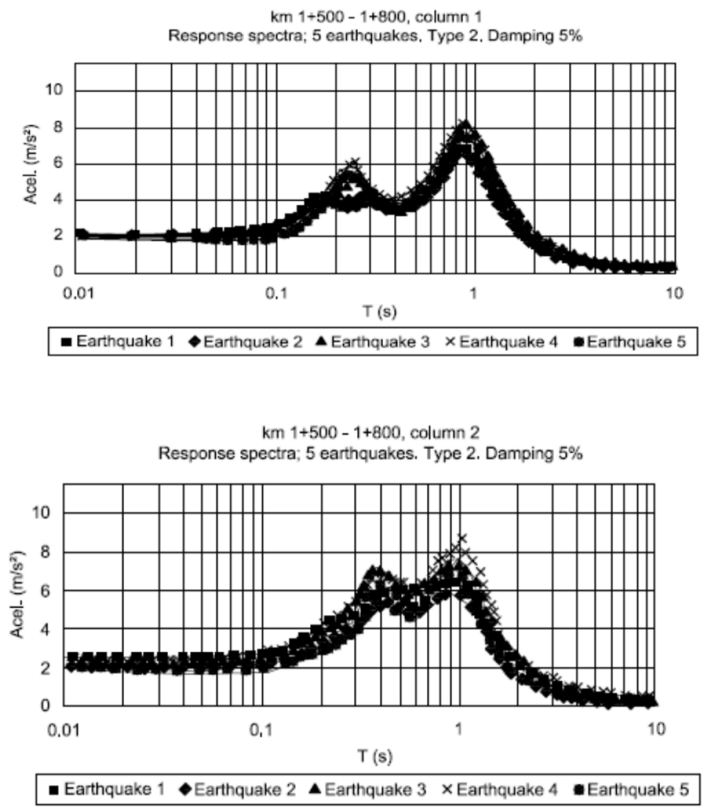

Fig. 17. Response spectra acceleration $\mathrm{km} 1+500-$ $\mathrm{km} 1+800$ action type 1 and action type 2 (after IST 2004a)

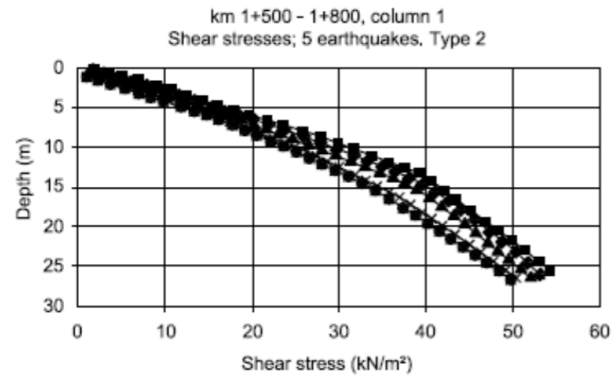

Earthquake $1 \bullet$ Earthquake $2 \Delta$ Earthquake $3 \times$ Earthquake $4 \bullet$ Earthquake 5

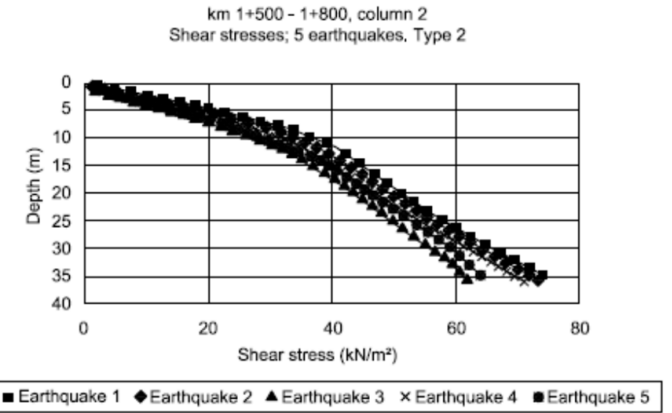

Fig. 18. Induced shear stress $\mathrm{km} 1+500-\mathrm{km} 1+800$, action type 1 and action type 2 (after IST 2004a)

\section{Liquefaction assessment}

Following 4.1.3. (2)-Part5-Eurocode 8 (1998b) "An evaluation of the liquefaction susceptibility shall be made when the foundations soils include extended layers or thick lenses of loose sand, with or without silt/clay fines, beneath the water level, and when such level is close to the ground surface".

The seismic shear stress $\tau_{\mathrm{e}}$ can be estimated from the simplified expression:

$$
\tau_{\mathrm{e}}=0.65 \alpha_{\mathrm{gr}} \gamma_{\mathrm{f}} \mathrm{S} \sigma_{\mathrm{vo}},
$$

where $\alpha_{\mathrm{gr}}$ is the design ground acceleration ratio, $\gamma_{\mathrm{f}}$ is the importance factor, $\mathrm{S}$ is the soil parameter and $\sigma_{\mathrm{vo}}$ is the total overburden pressure. This expression should not be applied for depths larger than $20 \mathrm{~m}$. The shear level should be multiplied by a safety factor of [1.25].

The magnitude correction factors in EC8 follow the proposal of Ambraseys (1988) and are different from the NCEER (1997) factors. A comparison between the different proposals is shown in Table 3.

A new proposal with a summary of different authors presented by Seed et al. (2001) is shown in Figure 19.

Table 3. Magnitude scaling factors

\begin{tabular}{c|c|c|c}
\hline $\begin{array}{c}\text { Magnitude } \\
\mathrm{M}\end{array}$ & $\begin{array}{c}\text { Seed \& Idriss } \\
(1982)\end{array}$ & $\begin{array}{c}\text { NCEER } \\
(1997)\end{array}$ & $\begin{array}{c}\text { Ambraseys } \\
(1988)\end{array}$ \\
\hline 5.5 & 1.43 & 2.20 & 2.86 \\
\hline 6.0 & 1.32 & 1.76 & 2.20 \\
\hline 6.5 & 1.19 & 1.44 & 1.69 \\
\hline 7.0 & 1.08 & 1.19 & 1.30 \\
\hline 7.5 & 1.00 & 1.00 & 1.00 \\
\hline .0 & 0.94 & 0.84 & 0.67 \\
\hline 8.5 & 0.89 & 0.72 & 0.44 \\
\hline
\end{tabular}

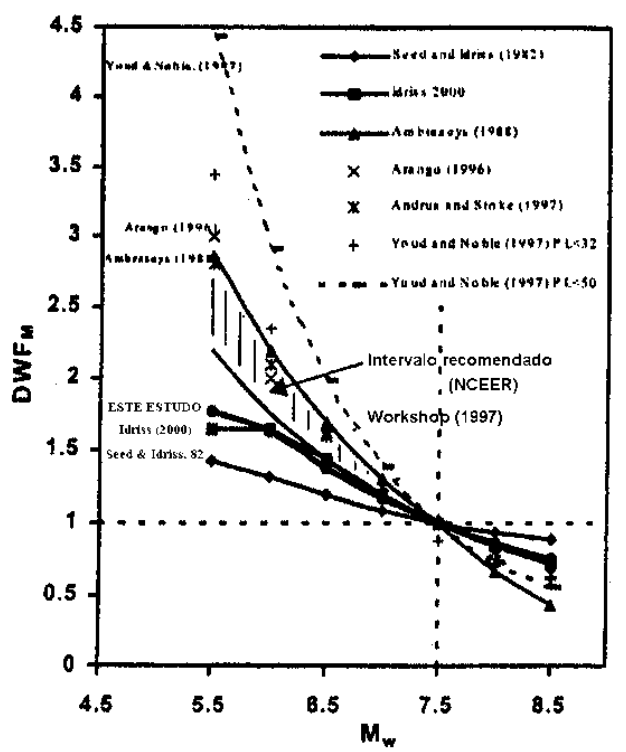

Fig. 19. Recommendations for correlations with magnitude (after Seed et al. 2001)

A new proposal presented by Cetin et al. (2001) for liquefaction analysis is shown in Figure 20. It is considered advanced in relation with the previous ones, as integrates: (i) data of recent earthquakes; 
(ii) corrections due the existence of fines; (iii) experience related with a better interpretation of SPT test; (iv) local effects; (v) cases histories related more than 200 earthquakes; (vi) Baysiana theory.

For liquefaction evaluation of sandy materials two methods are used, namely, based in laboratory tests or field tests The following laboratory tests are used: (i) cyclic triaxial tests; (ii) cyclic simple shear tests; (iii) cyclic torsional shear tests. Due to the difficulties to obtain high quality undisturbed samples in general field tests are used: SPT tests, CPT tests, seismic cone tests, flat dilatometer tests and tests to assess electrical properties (Sêco e Pinto et al. 1997).

For liquefaction assessment by shear wave velocities two methodologies are used: (i) methods combining the shear wave velocities by laboratory tests on undisturbed samples obtained by tube samplers or by frozen samples (Tokimatsu et al. 1991); (ii) methods measuring shear wave velocities and its correlation with liquefaction assessment by field observations (Stokoe et al. 1999).

EC8 uses corrective factors proposed by Ambraseys (1988), based in field tests that are different from the values proposed by Seed and Idriss (1982) and from the values proposed by NCEER (1997) based in laboratory tests. All the values are summarized in Table 3.

Due to the difficulties in performing CPT and SPT tests in soils with gravels some proposals to evaluate the susceptibility of liquefaction of these materials based in seismic tests with measurement of shear waves velocities Vs were proposed (Stokoe et al. 1999).

The post-liquefaction strength of silty materials is less than sandy materials, but superficial silty materials with moderate density are dilatant and with higher strength than clean sands (Youd, Gilstrap 1999).

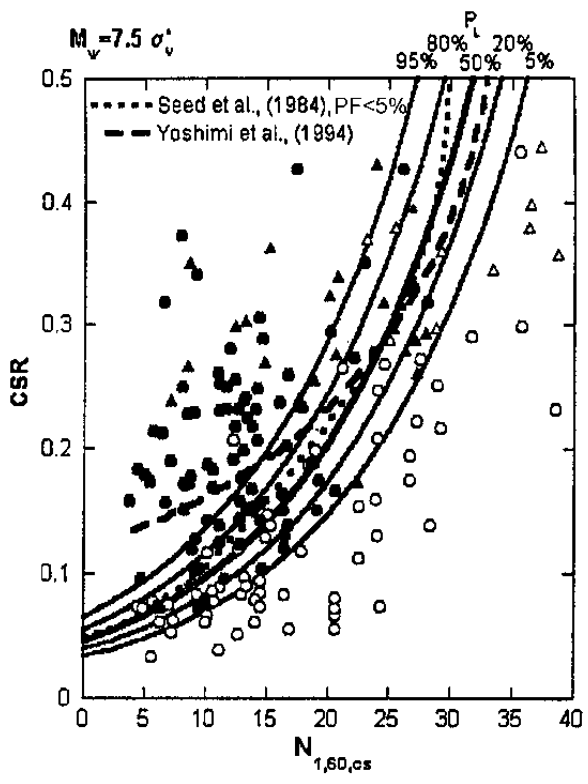

Fig. 20. Probabilistic approach for liquefaction analysis (after Cetin et al. 2001)
The authors have concluded that loose soils with IP $<12$ and $\mathrm{wa} / \mathrm{w}_{\mathrm{L}}>0.85$ are susceptible to liquefy and loose soils with $12<$ IP $<20$ and $\mathrm{wa} / \mathrm{w}_{\mathrm{L}}>0.85$ have higher strength to liquefaction and soils with IP $>20$ are not liquefiable.

It is important to refer that Eurocode 8 (1998b) Part 5 considers no risk of liquefaction when the ground acceleration is less than $0.15 \mathrm{~g}$ in addition with one of the following conditions: (i) sands with a clay content higher than $20 \%$ and a plasticity index $>10$; (ii) sands with silt content higher than $10 \%$ and $\mathrm{N}_{1}(60)>20$; and (iii) clean sands with $\mathrm{N}_{1}(60)>25$.

\section{Post liquefaction strength}

The topic related with the assessment of post liquefaction strength is not treated in EC8, but it seems that the following variables are important: fabric or type of compaction, direction of loading, void ratio and initial effective confining stress (Byrne, Beaty 1999).

A relationship between SPT $\mathrm{N}$ value and residual strength was proposed by Seed and Harder (1990) from direct testing and field experience (Fig. 21).

Ishihara et al. (1990) have proposed a relation of normalized residual strength and SPT tests, based on laboratory tests compared with data from back-analysis of actual failure cases (Fig. 22). Also Ishihara et al. (1990) by assembling records of earthquake caused failures in embankments, tailings dams, and river dykes have proposed the relation of Figure 23, in terms of the normalized residual strength plotted versus CPT value.

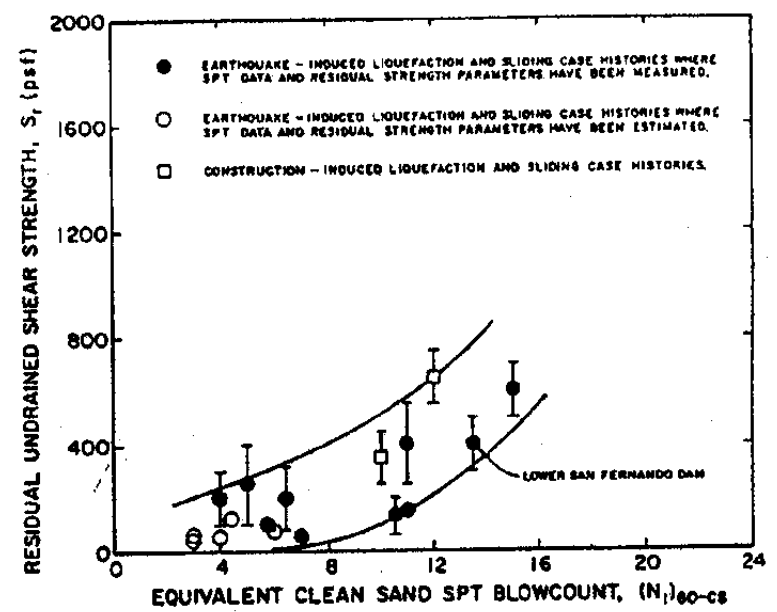

Fig. 21. Relationship between (N1) 60 and residual strength (after Seed, Harder 1990)

\section{Settlements assessment}

The susceptibility of foundations soils to densification and to excessive settlements is referred in EC8, but the assessment of expected liquefaction - induced deformation deserves more consideration.

By combination of cyclic shear stress ratio and normalized SPT N-values Tokimatsu and Seed (1987) have proposed relationships with shear strain (Fig. 24). 


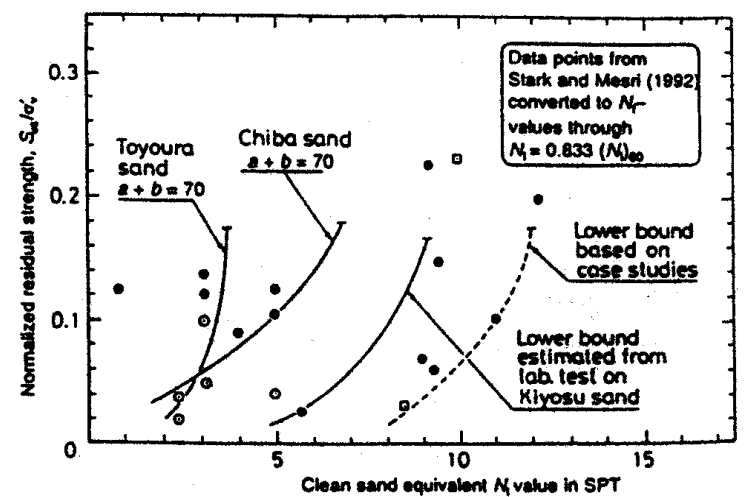

Fig. 22. Relation of normalized residual strength and SPT tests (after Ishihara et al. 1990)

To assess the settlement of the ground due to the liquefaction of sand deposits based on the knowledge of the safety factor against liquefaction and the relative density converted to the value of N1 a chart (Fig. 25) was proposed by Ishihara (1993).

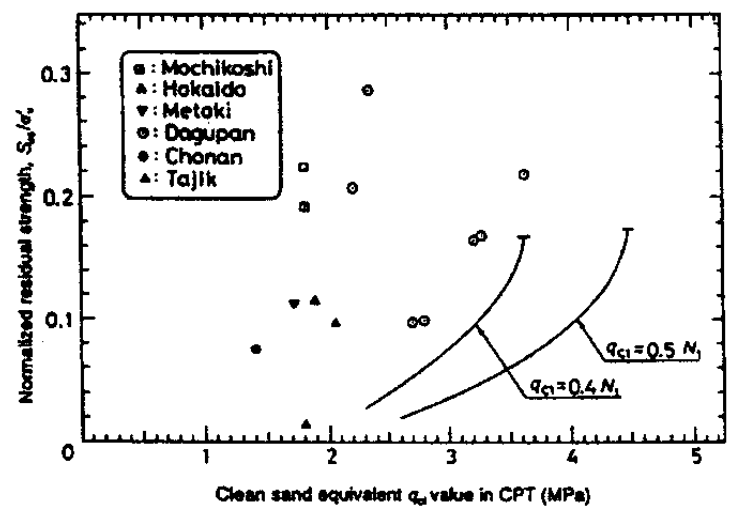

Fig. 23. Relation of normalized residual strength and CPT tests (after Ishihara et al. 1990)

\section{Remedial measures}

Following EC8 ground improvement against liquefaction should compact the soil or use drainage to reduce the pore water pressure. The use of pile foundations should be considered with caution due to the large forces induced in the piles.

The remedial measures against liquefaction can be classified in two categories (TC4 ISSMGE 2001; INA 2001): (i) the prevention of liquefaction; and (ii) the reduction of damage to facilities due to liquefaction.

The measures to prevent of occurrence of liquefaction include the improvement of soil properties or improvement of conditions for stress, deformation and pore water pressure. In practice a combination of these two methods is adopted.

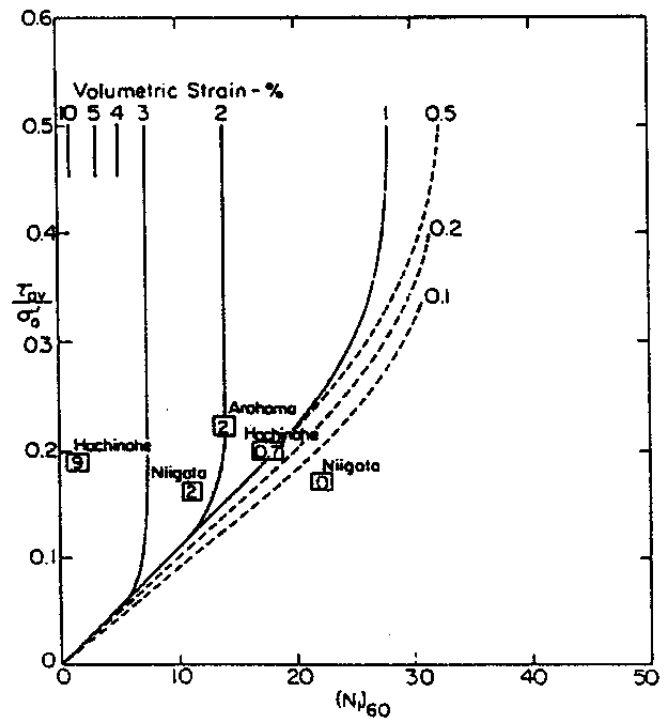

Fig. 24. Correlation between volumetric strain and SPT (after Tokimatsu, Seed 1987)

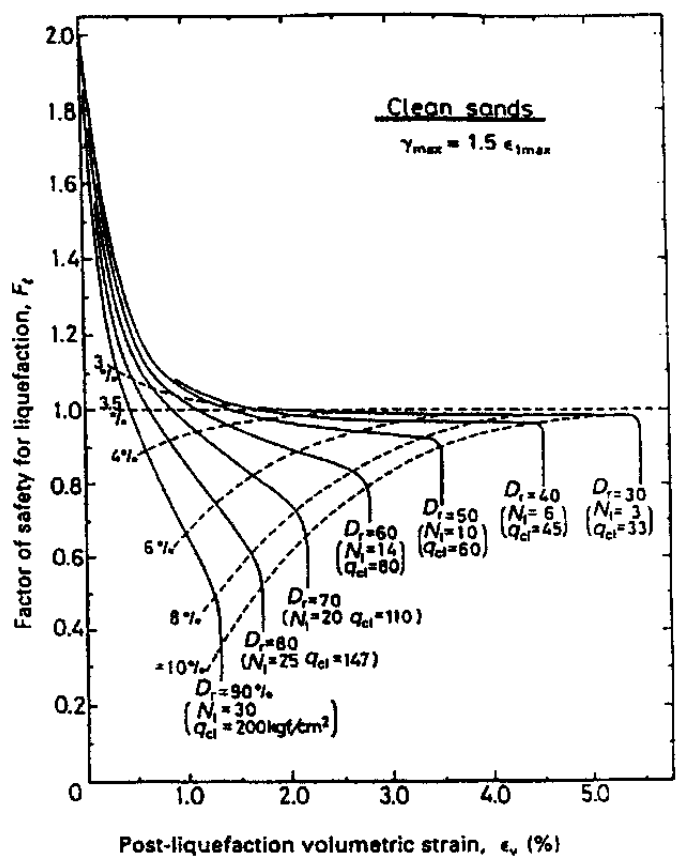

Fig. 25. Post cyclic liquefaction volumetric strain curves using CPT and SPT results (after Ishihara 1993)

The measures to reduce liquefaction induced damage to facilities include (1) to maintain stability by reinforcing structure: reinforcement of pile foundation and reinforcement of soil deformation with sheet pile and underground wall; (2) to relieve external force by softening or modifying structure: adjusting of bulk unit weight, anchorage of buried structures, flattering embankments. 


\section{Liquefaction evaluation}

The liquefaction potential evaluation was performed only by field tests taking into account the disturbance that occurs during sampling of sandy materials (Jeremias et al. 2007).

In this analysis attention was drawn for SPT and CPT tests as the seismic tests have only been used when soil contains gravel particles.

The shear values were computed from a total stresses model, that gave results on the conservative side using the code "SHAKE 2000".

Just as an example Figure 26 illustrates the differences between the total stress model and an analysis in effective stresses using the computer program DYNAFLOW for the Vasco da Gama bridge in Tagus river and with the same type of alluvia materials.

Corrections related with SPT test results due to the depth effect and the equipment were performed following the recommendations of EC8 (1998b).

The sieve curves of materials $\mathrm{a}_{1}$ and $\mathrm{a}_{2}$ are shown in Figures 27 and 28.

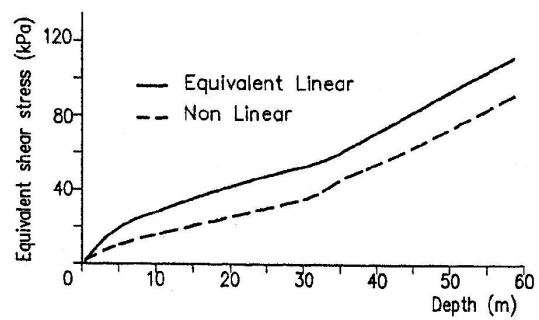

Fig. 26. Equivalent shear stresses computed from SHAKE and DYNAFLOW codes (after Sêco e Pinto, Oliveira 1998)

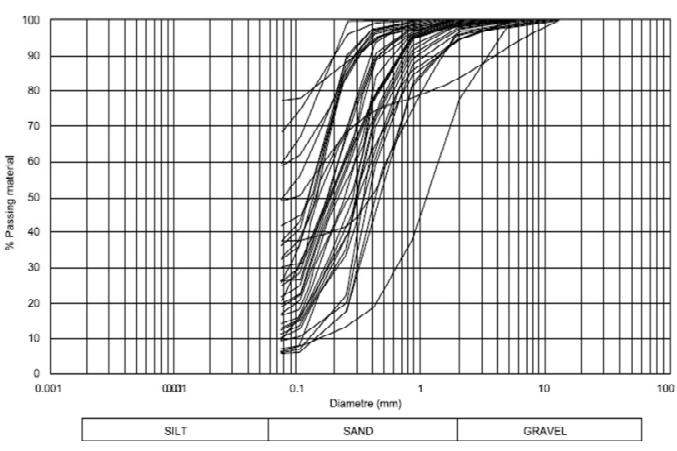

Fig. 27. Sieve curves for material $\mathrm{a}_{1}$

Taking into account that we are dealing with underwater materials, the sieve curves exhibit percentages of fines lower than in reality, as a consequence of the washing effect during the sampling.

The liquefaction potential evaluation was given in tables and the columns have included the following data: (i) columns 1 to 4 , reference to the pier, type of test (SPT or CPT), depth of the test and thickness of the layer; (ii) columns 5 and 6 , values of $\mathrm{N}_{\mathrm{m}}(\mathrm{SPT})$ and $\left(\mathrm{q}_{\mathrm{c}}\right)_{\mathrm{m}}$ (CPT); (iii) columns 7 and 8 , effective overburden pressure $\left(\sigma^{\prime} \mathrm{o}\right)$ and correction factor $\left(\mathrm{C}_{\mathrm{N}}\right)$; (iv) columns 9 and 10 , normalised values $\mathrm{N}_{1}$ (60) (SPT) (for shallow soils due to disturbance effects reduced $\mathrm{C}_{\mathrm{N}}$ values were

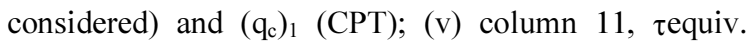
(equivalent shear stress value computed for action type 2 related with the highest magnitude 7.5); (vi) column $12\left(\tau / \sigma^{\prime}\right.$ o ratio value), column $13\left(\tau / \sigma^{\prime}\right.$ o ratio value with a safety factor of 1.1$)$, column $14\left(\tau / \sigma^{\prime}{ }_{0}\right.$ ratio value with the safety factor of 1.25); (vii) column 15, Ref. (reference of the analysed SPT or CPT value); (viii) column 16, liquefaction susceptibility analysis. Taking into account the dilatant behavior of the material observed in the CPT tests and the values of the pore pressures developed in the cyclic torsional shear tests, where the registered values of the pore pressures rarely reach the value of $80 \%$, being frequently below $60 \%$, a safety factor of 1.1 can be considered sufficient. Nevertheless, at the present case, a conservative analysis was performed, with a safety factor of 1.25 being adopted, as recommended in EC8, Part 8.5 (1998b).

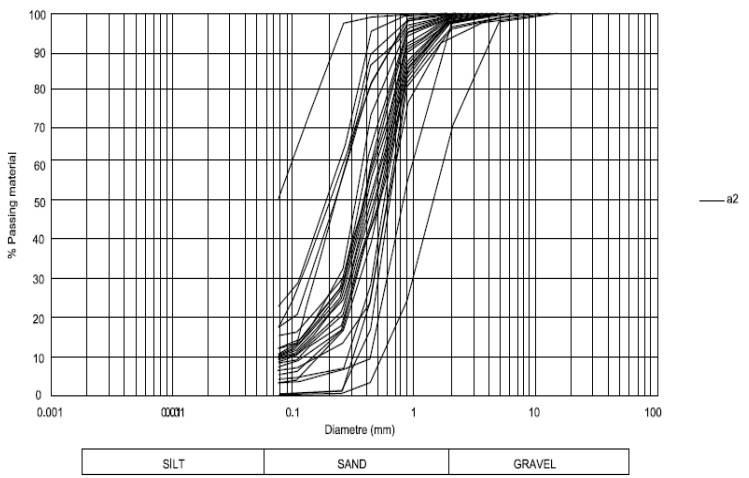

Fig. 28. Sieve curves for material a2

Table 4 presents an application of liquefaction evaluation for material $a_{1}$ and material $a_{2}$. The liquefaction potential evaluation, by SPT and CPT tests, is shown in Figures 29 and 30.

Taking into account the Figures 24 and 25 the estimated settlements of materials $\mathrm{a}_{1}$ and $\mathrm{a}_{2}$ are between $40 \mathrm{~mm}$ to $150 \mathrm{~mm}$.

\section{Pile load tests}

\section{Introduction}

Following Eurocode 7 (1997) pile design can be performed by (COBA, PC\&A, CIVILSER e ARCADIS 2005a, 2005b):

$$
\begin{aligned}
& \text { - prescriptives measures and comparable } \\
& \text { experience; } \\
& \text { - design models; } \\
& \text { - use of experimental models and load tests; } \\
& \text { - observational method. }
\end{aligned}
$$


Table 4. Evaluation of liquefaction potential material $\mathrm{a}_{1}$ and material $\mathrm{a}_{2}$

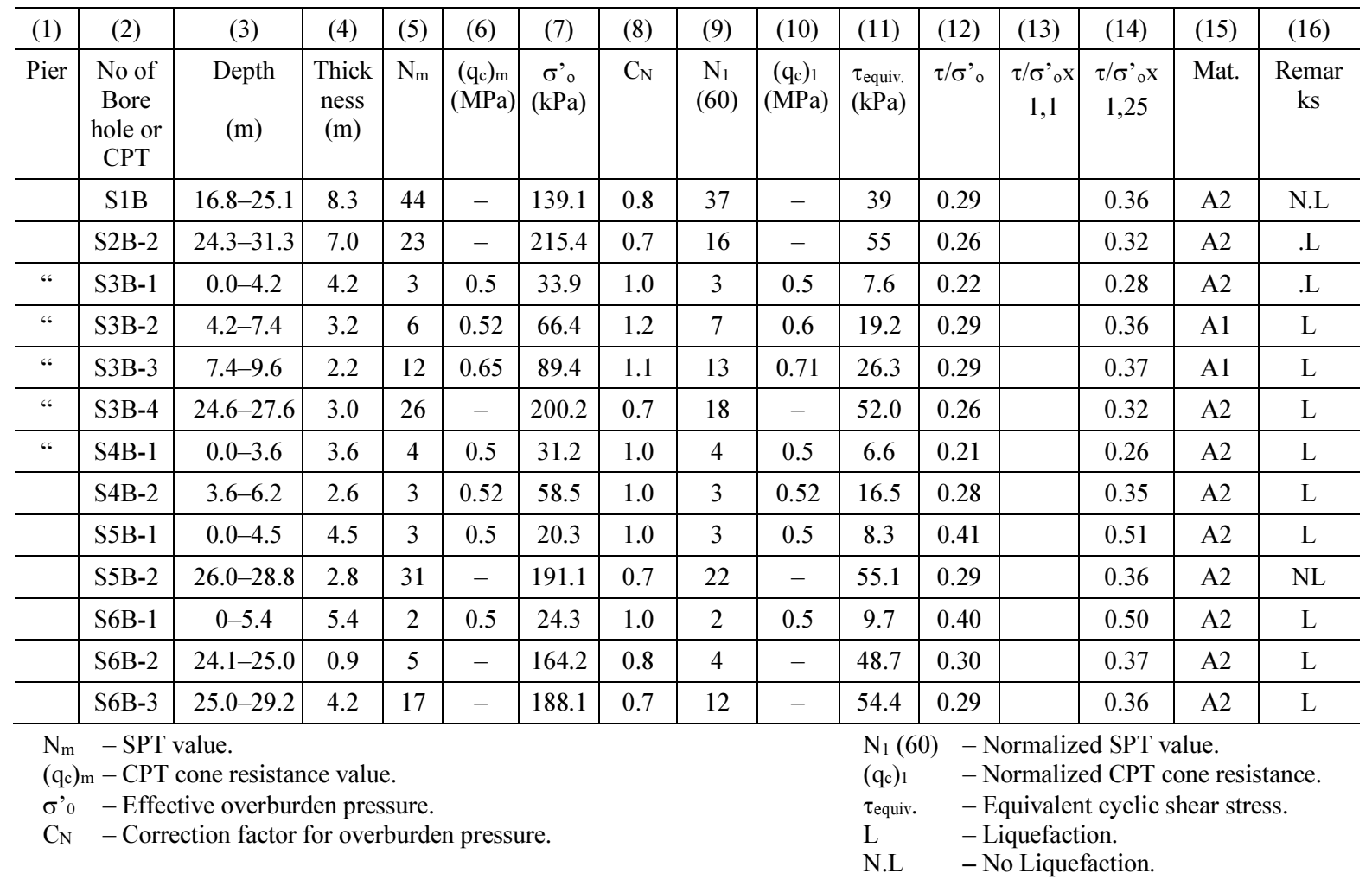

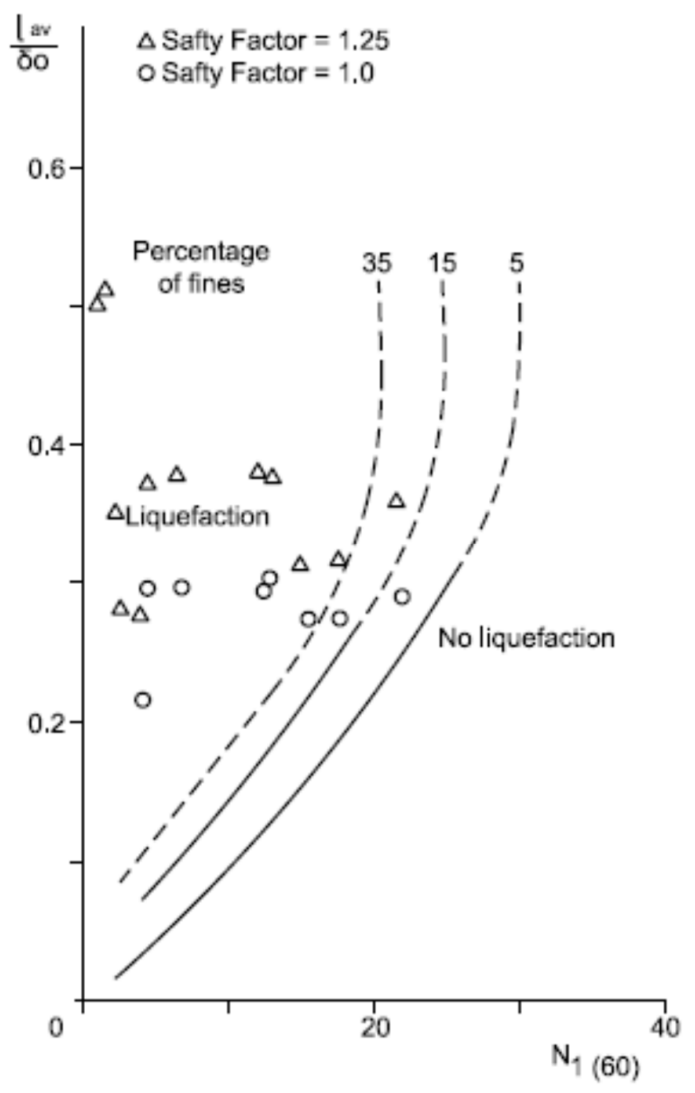

Fig. 29. Liquefaction potential evaluation by SPT tests
The piles of Leziria bridge were designed by (Ferreira et al. 2008):

i) design models;

ii) pile load tests that have given information about the characteristics of gravel materials and techniques of driving the metallic casings;

iii) comparable experience.

Pile load tests were performed with the following purposes:

i) to determine the response of a representative pile and the surrounding ground to load, both in terms of settlements and limit load;

ii) to check the performance of individual piles and to allow judgment of the overall pile foundation;

iii) to assess the suitability of the construction method.

Load tests were carried out on trial piles which were built for test purposes before the final design.

The results of load tests were used to calibrate the design parameters and so to optimize the suggested values for pile lengths, based only on the interpretation of site investigation and laboratory and in situ test results.

The number of pile tests were selected taking into consideration the following aspects:

- the ground condition and the spatial variation; 
- the geotechnical category of the structure;

- past experience related the use of same type of piles in same ground conditions;

- planning of the works.

The experimental piles for static and dynamic tests were located at $\mathrm{Km} 8+200$ where the pile was embedded 1 diameter in the Miocene, at $\mathrm{Km} 7+900$ where the pile was embedded 3 diameters in the gravel materials, and at $\mathrm{Km} 5+400$ where the pile was embedded 3 diameters in the Miocene (COBA, PC\&A, CIVILSER e ARCADIS 2005a, 2005b, $2005 \mathrm{c})$. Table 5 gives a summary o pile type and location.

In each place a $800 \mathrm{~mm}$ diameter pile was built for static test, two reaction piles with $1500 \mathrm{~mm}$ of diameter, $3.5 \mathrm{~m}$ apart from the pile test, and a fourth $800 \mathrm{~mm}$ diameter pile, $5.5 \mathrm{~m}$ apart from the first pile, for dynamic test.

To perform pile load tests 7 piles $1.5 \mathrm{~m}$ diameter and 7 piles $0.8 \mathrm{~m}$ diameter piles were built.

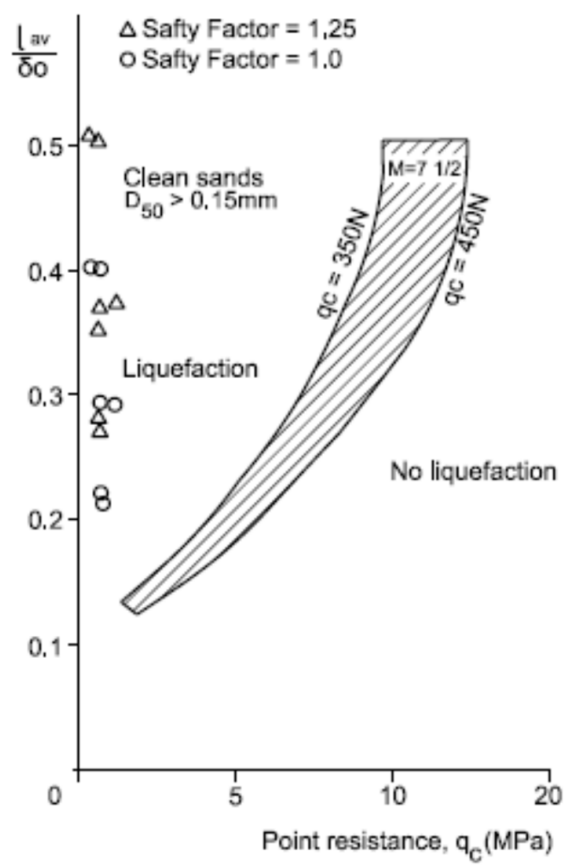

Fig. 30. Liquefaction potential evaluation from CPT tests

Table 5. Summary of pile type and location

\begin{tabular}{c|c|c|c}
\hline $\begin{array}{c}\text { Piles } \\
(\mathrm{Km})\end{array}$ & $\begin{array}{c}\text { Diameter } \\
(\mathrm{m})\end{array}$ & $\begin{array}{c}\text { Pile } \\
\text { Embedding }\end{array}$ & Type LoadTest \\
\hline $5+400$ & 0.8 & $3 \varnothing(\mathrm{M})$ & $\begin{array}{l}\cdot \text { Vertical } \\
\cdot \text { Dynamic }\end{array}$ \\
\hline $7+900$ & 0.8 & $3 \varnothing(\mathrm{a} 3)$ & $\begin{array}{l}\text { Vertical } \\
\cdot \text { Dynamic }\end{array}$ \\
\hline $8+200$ & 0.8 & $1 \varnothing(\mathrm{M})$ & $\begin{array}{l}\text { Vertical } \\
\cdot \text { Dynamic }\end{array}$ \\
\hline $4+750$ & 1.5 & $3 \varnothing(\mathrm{M})$ & $\begin{array}{l}\text { Horizontal } \\
\cdot \text { Dynamic }\end{array}$ \\
\hline
\end{tabular}

\section{Vertical pile load tests}

The methodology to perform static vertical pile load tests has followed "Axial Pile Loading Test, Suggested Method" recommended by ISSMGE and published in ASTM D1143 (1981).

The purpose was to incorporate the contribution of all the ground layers and their influence in the deformations until a depth of 5 diameters, unless the bedrock was situated at upper level.

Vertical load tests were performed on 3 piles.

For the vertical load test the following equipments were installed: 2 mechanical dial gauges, electrical displacement transducers (Fig. 31) with removable extensometers (Fig. 32), with a resolution of $10^{-6}$, and anchors, 1 temperature sensor, 1 tilmeter, 1 hydraulically operated pump, 2 hydraulic jacks and 1 optical level.

A general view for vertical pile load tests is presented in Figure 33.

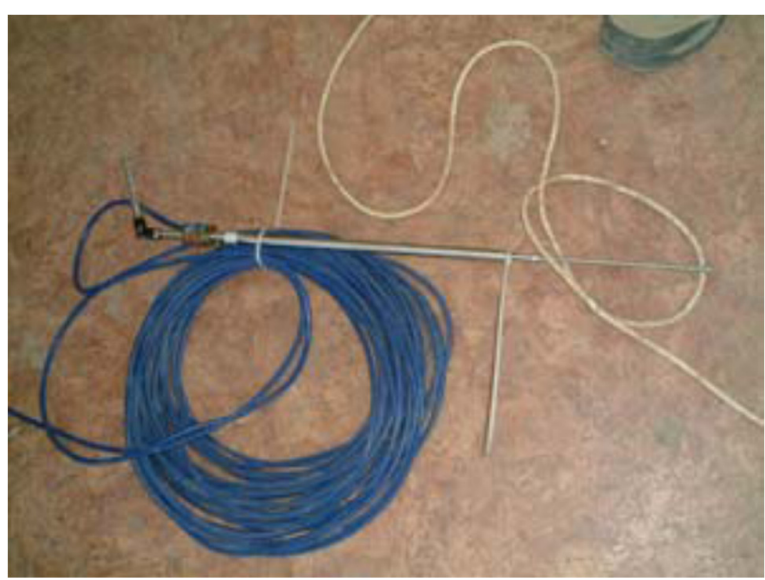

Fig. 31. Displacement transducers

For the vertical pile load tests a maximum load of $9100 \mathrm{kN}$ was applied, i.e. 3.25 times the service load. The loads were applied in two cycles of load and unload, with a maximum load of service load for the first cycle and the loads were applied in 4 increments.

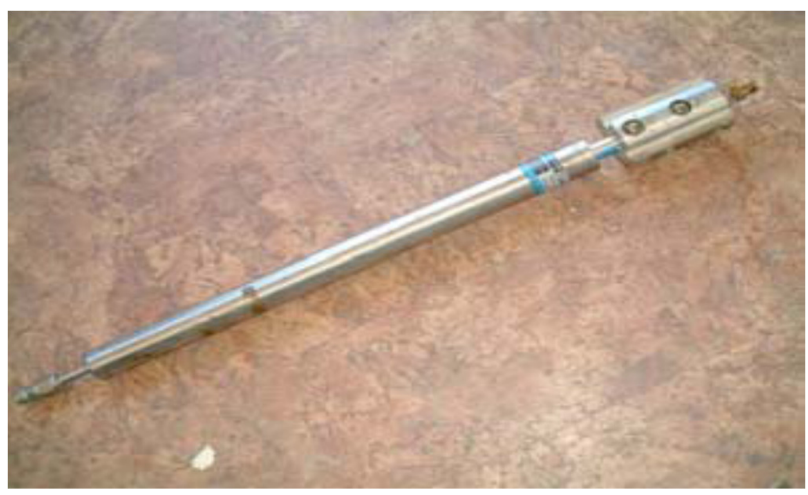

Fig. 32. Recovery extensometers 
In the second cycle the loads were applied in 19 increments.

The number of load increments and the cycles of load and unload were defined with the purpose to reach some conclusions related to deformations, creep effects and ultimate load.

The load - settlement curves for 3 pile tests are shown in Figure 34.

Failure loads were defined as settlement equal to $10 \%$ of the pile diameter, i.e. at $80 \mathrm{~mm}$ settlement.

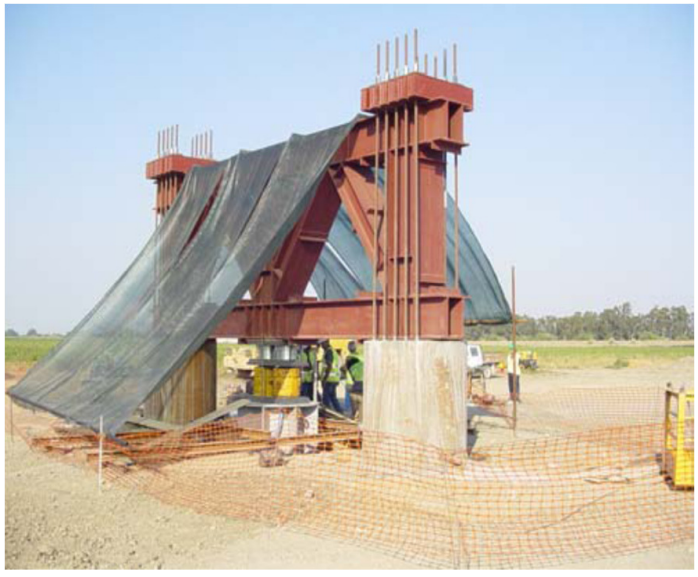

Fig. 33. General view for vertical pile load tests (after Ferreira et al. 2008)

\section{Horizontal pile load tests}

The horizontal load tests were performed in two piles of $800 \mathrm{~mm}$ and $1500 \mathrm{~mm}$ of diameter located at $\mathrm{km} 5+400$. The maximum load was $600 \mathrm{kN}$ to mobilize a displacement of $8 \mathrm{~cm}$ and the loads were applied in steps of $75 \mathrm{kN}$ (ICIST-IST 2005).
For the horizontal load tests the following equipments were installed:

- clinometers;

- vibrating wire transducers;

- load cells;

- retrieval extensometers;

- inclinometer tubes to measure horizontal displacements;

- temperature device.

The loading program consisted of: 10 load increments from $50 \mathrm{kN}$ to $500 \mathrm{kN}$.

The load displacement curve measured is shown in Figure 35.

The measured rotations values versus loads are shown in Figure 36.

Figure 37 shows a comparison between the bending moments values obtained by the tests and by the analyses for different values of $\mathrm{k}=2500 \mathrm{kPa}$, $5000 \mathrm{kPa}$, and $10000 \mathrm{kPa}$.

\section{Dynamic pile tests}

Dynamic pile tests were performed in 9 piles with diameters of $800 \mathrm{~mm}$ and $1500 \mathrm{~mm}$.

The piles were instrumented with:

-4 pairs of acelerometers (Fig. 38).

-4 transdutors.

- topographic equipment.

A dynamic test view is shown in Figure 39.

During the tests the height of the hammer fall was increasing from $0.2 \mathrm{~m}$ to $3.0 \mathrm{~m}$ in steps of $0.2 \mathrm{~m}$.

The point resistance $(\mathrm{Rb})$ and the lateral resistance (Rs) for pile E 800-2 is shown in Figure 40.

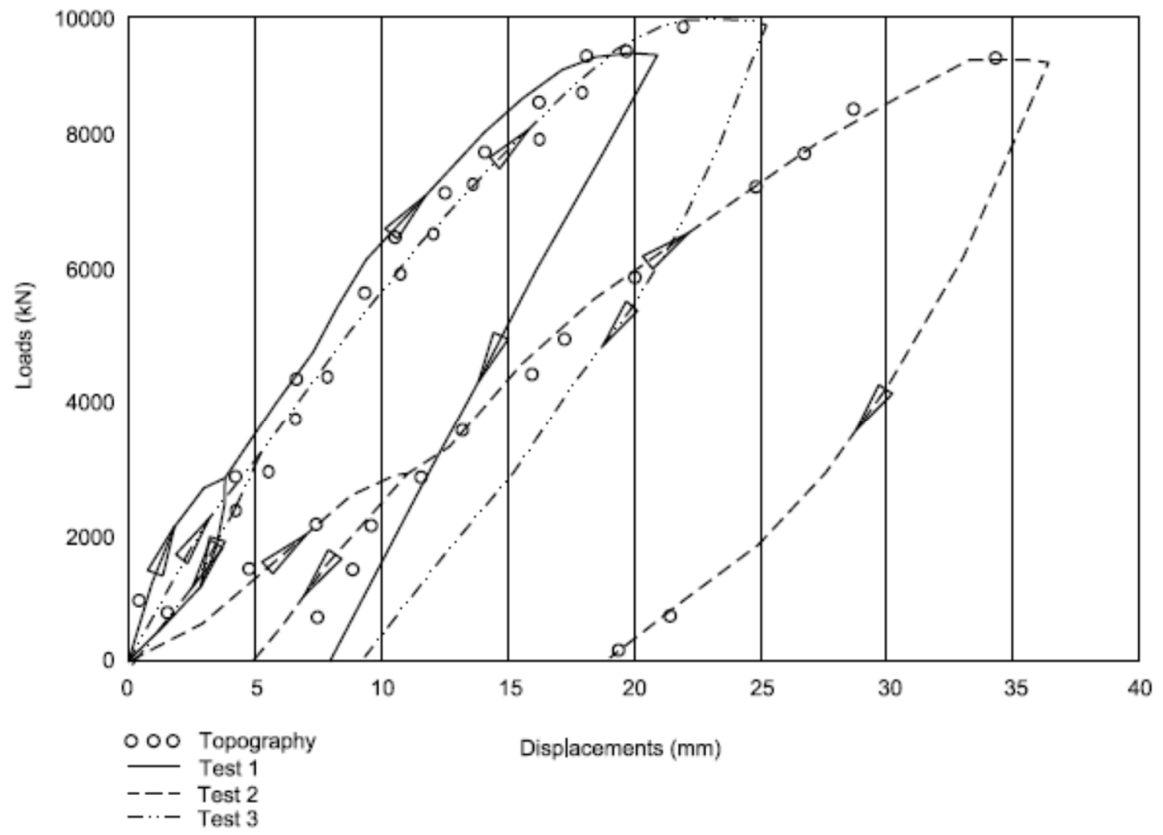

Fig. 34. Load settlement curves for vertical tests (after ICIST-IST 2005) 


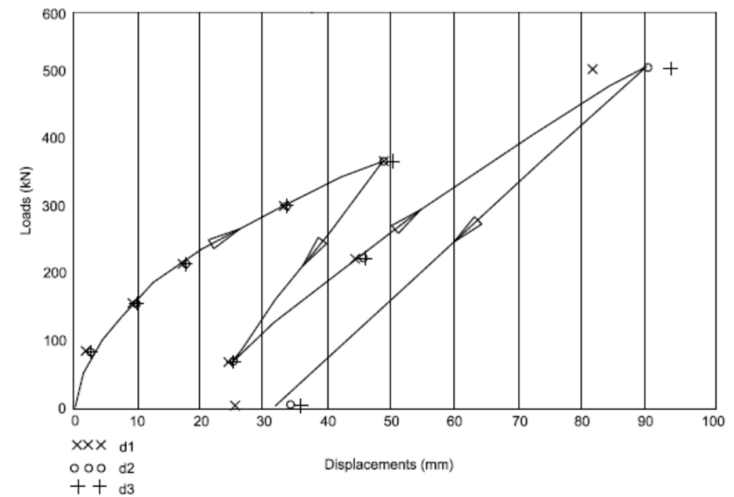

Fig. 35. Measured load displacement curve for horizontal tests (after ICIST-IST 2005)

It is important to stress that the results of dynamic tests have confirmed the results of static tests pointing the higher contribution of the lateral resistance in comparison with the point resistance.

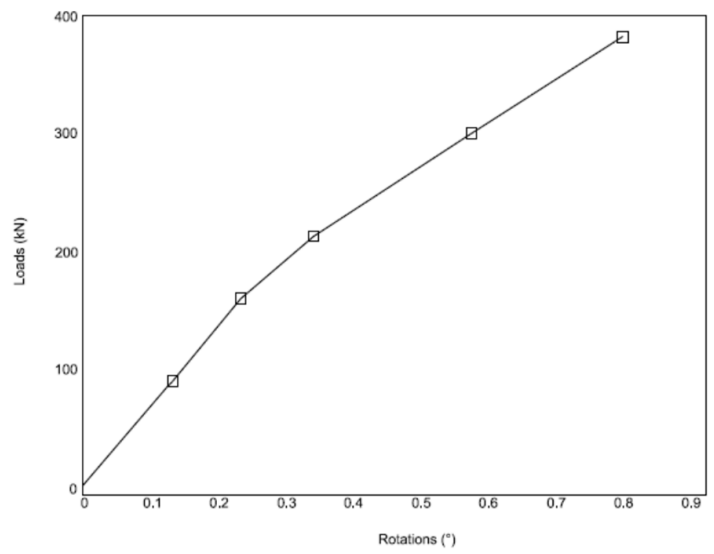

Fig. 36. Measured load rotations curve for horizontal tests (after ICIST-IST 2005)

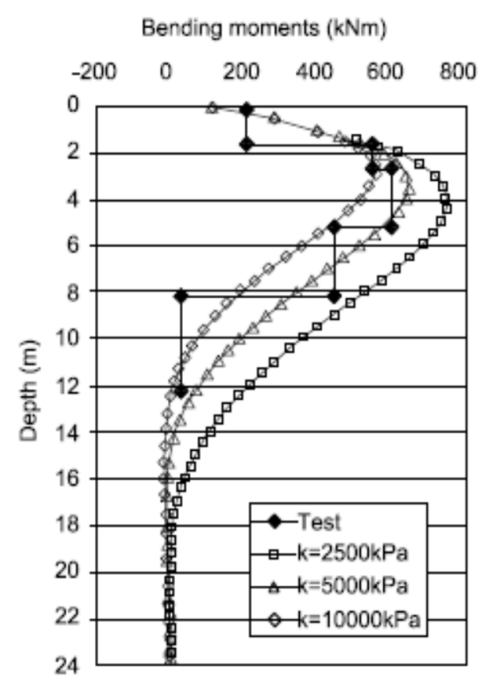

Fig. 37. Bending Moments (after ICIST-IST 2005)

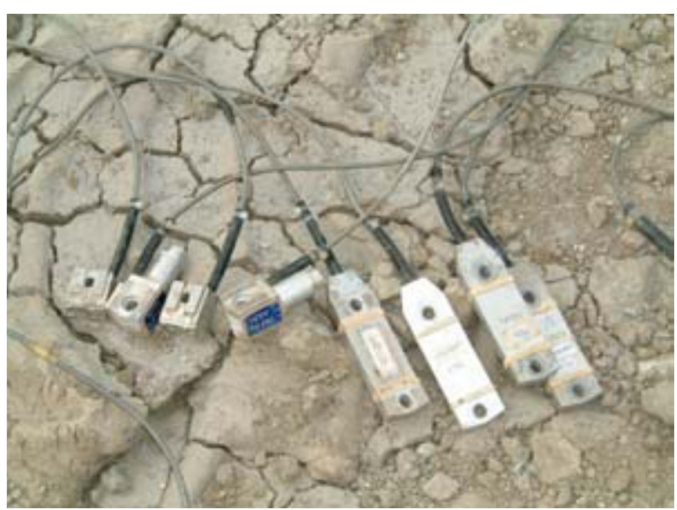

Fig. 38. Transducers and accelerometers

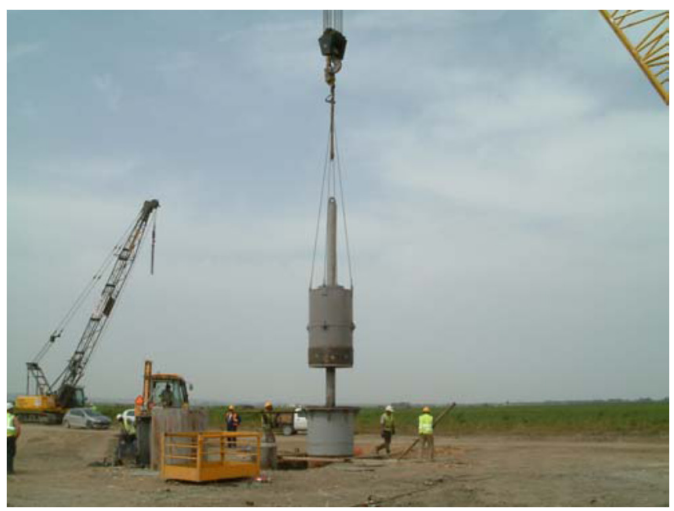

Fig. 39. Dynamic test (after Ferreira et al. 2008)

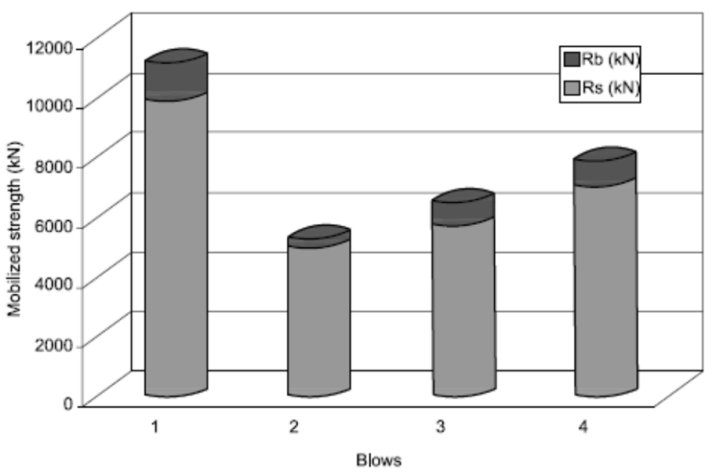

Fig. 40. Mobilized resistances (after ICIST-IST 2005)

Part 4

"The important thing in science is not so much to obtain new facts as to discover new ways of thinking about them".

(Sir W. Bragg, British Scientist, 1968)

\section{Construction aspects}

The most important construction aspects are listed below:

i) After the temporary works through the execution of sheet piles the anchorage of the pontoon was done, in order to assure the 
stability during the driving of the casings. The system had the purpose to assure the verticality of the casings.

ii) Transportation of the metallic $2.2 \mathrm{~m}$ diameter and $17 \mathrm{~mm}$ thick casing. This casing was driven by a high capacity vibrator and a penetration of 1 to $2 \mathrm{~m}$ in geotechnical unit $\mathrm{a}_{\mathrm{oa}}$ was assured.

Driven piles were installed by joint venture subcontractor Volker Stevin - Ballast Nedam. Large barge mounted cranes were used to drive each pile as one piece. A handling capacity around $58 \mathrm{t}$ was necessary by the cranes and the hammer to drive the piles into position.

Subsequently a guidance system was used to drive the casing 1 diameter into gravel materials or into a compacted ground with a minimum value of SPT 10 blows.

i) Progress of the excavation with a $2.2 \mathrm{~m}$ diameter "hammergrab" of in order to reach the Miocene. For the wall stabilization polymers materials manufactured in a central located in the left bank were used. For the polymer control $\mathrm{pH}$ tests, density and viscosity tests, as well sand content tests were performed.

ii) After the excavation and the decantation of the polymer the reinforcement with the pipes for the cross-hole tests was installed. To assure a minimum cover of $12 \mathrm{~mm}$ centralizers were placed.

i) Concreting of the piles with the use of "tremie" and pumping was done at a rate of $50 \mathrm{~m}^{3}$ /hour.

The duration of these 5 phases was 2.5 days.

In the construction procedure proposed in the Basic Design (COBA, PC\&A, CIVILSER e ARCADIS, 2004b) the pile caps for piers P1 and P2 were performed within cofferdams constructed by sheet piles driven into the mud materials trough equipments installed in barges. The voids under the casings were stabilized trough the use of polymers.

For caps P3 to P7 the constructive procedure consisted on the construction of prefabricated caissons in dry dock. The caissons were transported from onshore casted in situ and subsequently the metallic casings were driven trough the holes of the bottom slab and the openings under the casings being stabilized trough the use of polymers.

During the Final Design a solution of prefabricated caissons was developed with large caissons for piers $\mathrm{P} 1 \mathrm{C}$ and $\mathrm{P} 2 \mathrm{C}$ and small caissons for piers $\mathrm{P} 3 \mathrm{C}$ to P7C (COBA, PC\&A, CIVILSER e ARCADIS, 2005h).

A view of North Viaduct construction is shown in Figure 41.

To avoid excavations of the protection dykes a parallel way (transient viaduct) was built (Fig. 42).

A view of South Viaduct construction is shown in Figure 43.

The placement of pile casing is shown in Figure 44 .

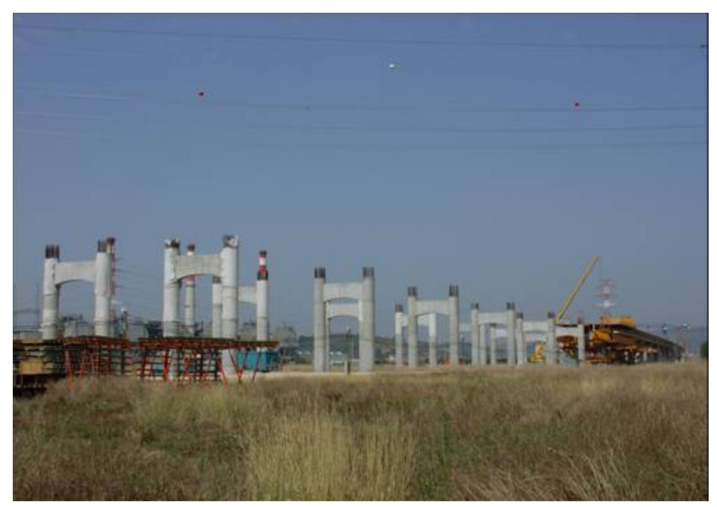

Fig. 41. Construction of North Viaduct

The pre-fabricated caissons were temporary supported by the casings of the definitive piles. With the support of hydraulic cylinders the temporary metallic structure was uplifted and subsequently the caisson was moved downward until the design level.

After the sealing of the joints between the piles and the bottom slab the water inside the caissons was removed by pumping.

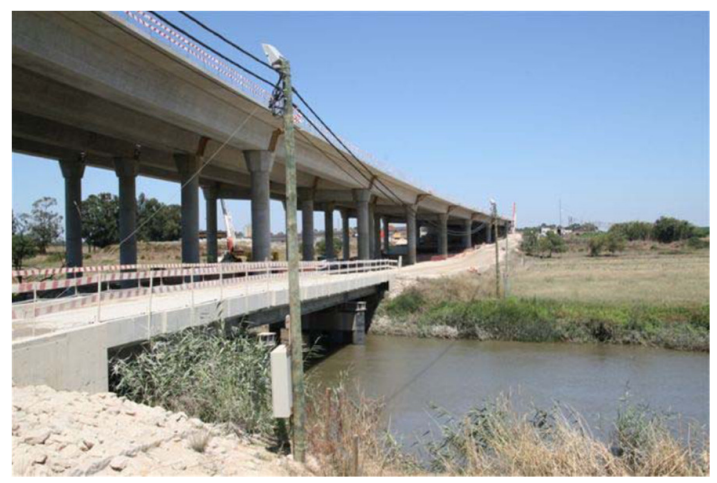

Fig. 42. Parallel Way

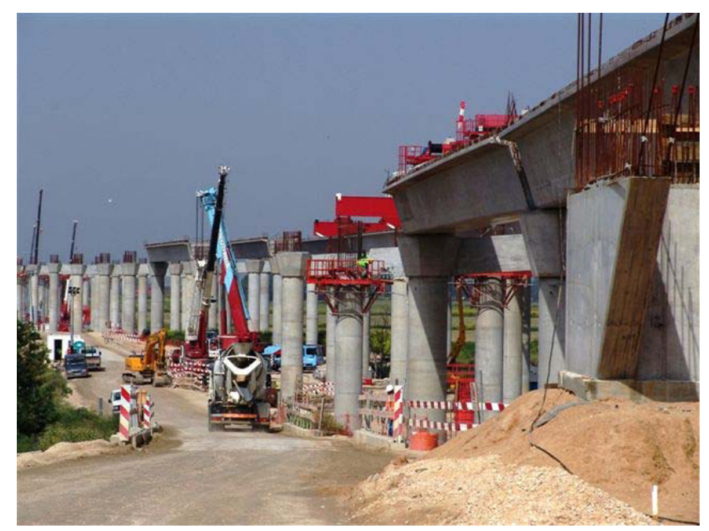

Fig. 43. Construction of South Viaduct

The placement of pile reinforcement and tremi pipes are shown in Figures 45 and 46.

In Figures 47 to 49 a caisson view, a pier under construction and a general view of the construction works are presented. 


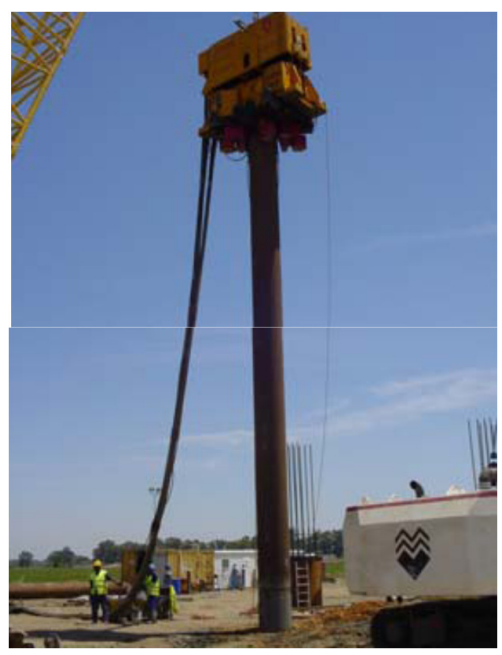

Fig. 44. Placement of pile casing (after Ferreira et al. 2008)

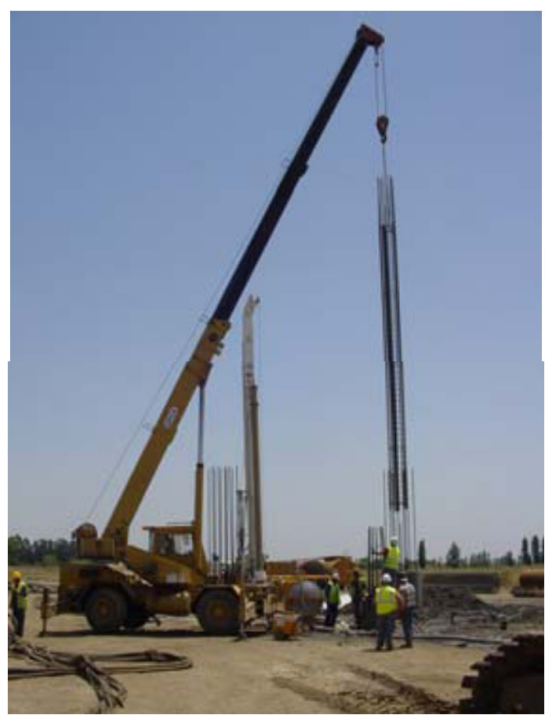

Fig. 45. Placement of pile reinforcement (after Ferreira et al. 2008)

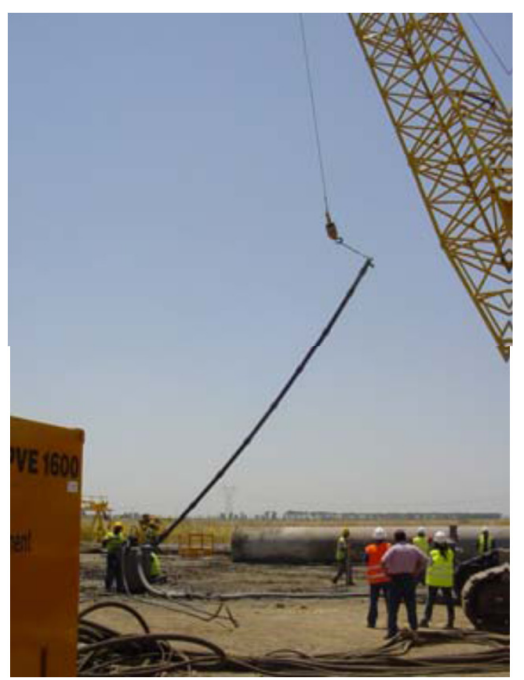

Fig. 46. Placement of tremie pipes (after Ferreira et al. 2008)

\section{Reception tests for piles}

The development and implementation of non destructive techniques of pile tests have experienced a great increment as the use of core sampling and load tests to control the final quality of the piles are very costly and can only be performed in a small number of piles.

Anomalies that impair the integrity of a pile and that are expected to be identified by integrity tests include the presence of material of poorer quality than expected (locally and overall) and variations in the cross section of the shaft (e.g., crack, necking, and bulb) (Sêco e Pinto, Rodrigues 1989).

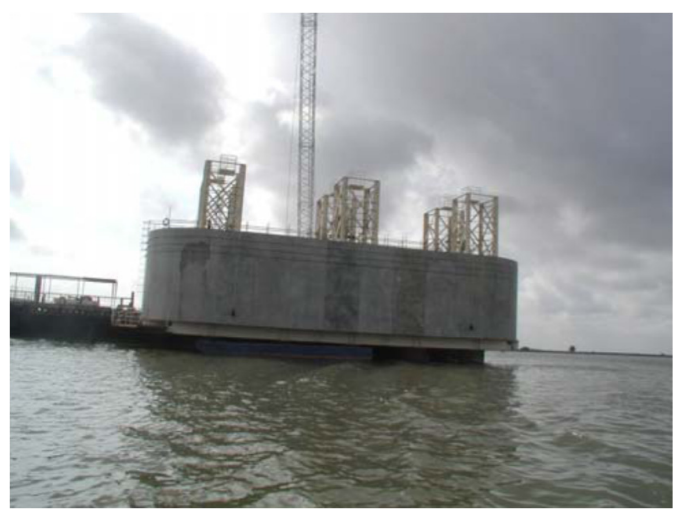

Fig. 47. View of Caisson (courtesy of Perry da Câmara)

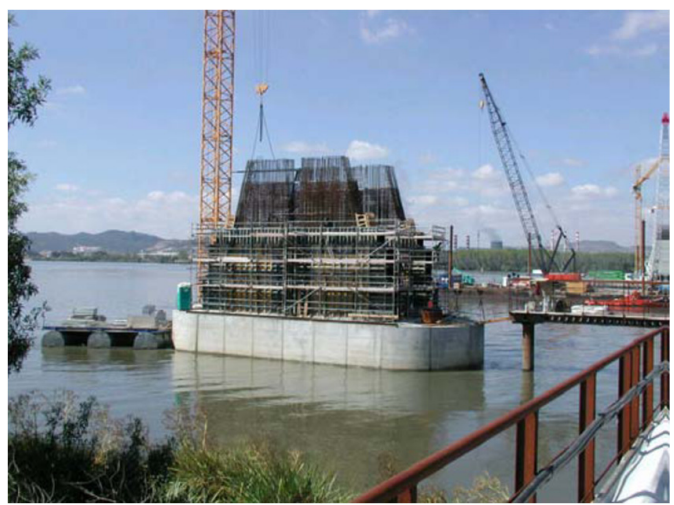

Fig. 48. Pier under construction (courtesy of Perry da Câmara)

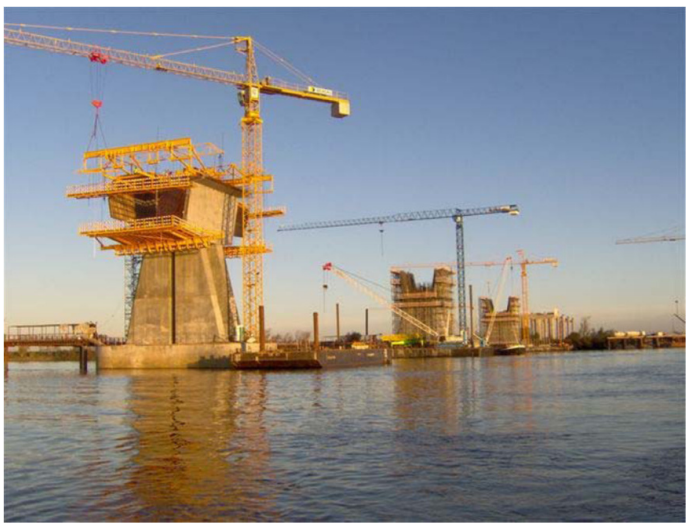

Fig. 49. General view of the construction works (courtesy of Perry da Câmara) 
Also sonic diagraphy tests were performed and a continuous record through the length of the pile of the velocity of sonic waves between the source and the geophones introduced in two pipes attached to the pile reinforcement was done.

The sound velocity in concrete is around $4000 \mathrm{~m} / \mathrm{s}$, but in the presence of anomalies, i.e. fissures, segregations or soil inclusions this value decreases.

The quality of the results depends of the following requirements:

i) Use of metallic tubes with diameter between 35 and $60 \mathrm{~mm}$;

ii) The number of tubes depends of the pile diameter:

diâmeter $<0.60 \mathrm{~m}=2$ tubes

$0.60 \mathrm{~m}<$ diâmetro $<1.20 \mathrm{~m}=3$ tubes placed $120^{\circ}$ apart diâmetro $>1.20 \mathrm{~m}=4$ tubes, as a minumum;

iii) The connection between the tubes should be done by joints;

iv) A good contact between the tube and the concrete;

v) At the bottom of the tubes a sealing should be placed to avoid the uplift of the sediments or concrete;

vi) The tubes should be connected to the pile reinforcement along the total length;

vii) The top level of the tubes should be $0.5 \mathrm{~m}$ above the pile head, as a minimum;

viii) The tubes should be placed vertical and parallel to the pile reinforcement;

ix) The pile test should be performed 3 days after the concreting, as a minimum.

Figure 50 shows a pile view with 4 tubes.

Taking into account that piles were $1.52 \mathrm{~m}$ diameter 4 tubes $90^{\circ}$ apart were placed.

In the experimental pile tests located at KM $5+$ 400, KM $7+900$, KM $8+200$ a verification of integrity tests by cross hole tests were performed.

For piles $1.5 \mathrm{~m}$ diameter 4 tubes were placed. The records and tests interpretation were presented by GEOSOLVE (2005a, 2005b, 2005c).

\section{Some problems during pile construction}

\section{Introduction}

Some problems have occurred during piles construction in the Main Bridge due to the gravel and cobbles dimensions. Due to the difficulties to interpret SPT tests in sandy gravel materials Daniel et al. (2004) have conducted a research trough: (i) a comparison between tests with SPT sampler $(5.08 \mathrm{~cm})$ and other samplers with higher dimensions, namely japonese with $7.3 \mathrm{~cm}$, italian with $14 \mathrm{~cm}$ and american with $7.6 \mathrm{~cm}$, with the purpose to define corrective factors incorporating : (i) the energy transmitted by driven equipment; (ii) using discrete models (DEM) for a better understanding of the crushing effects between the links of particles of gravel materials; (iii) using the theory of waves propagation associated with the records of axial forces, velocity of rods penetration for a better understanding of the particles displacements response and grain dimensions. The outcome of this research is summarized in Figures 51 and 52.

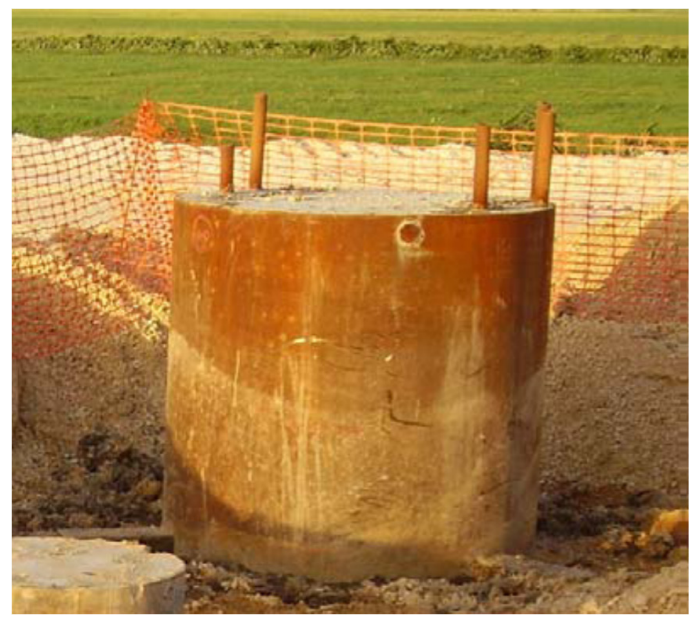

Fig. 50. 4 tubes for crosshole tests in a $1.5 \mathrm{~m}$ diameter pile (after Ferreira et al. 2008)

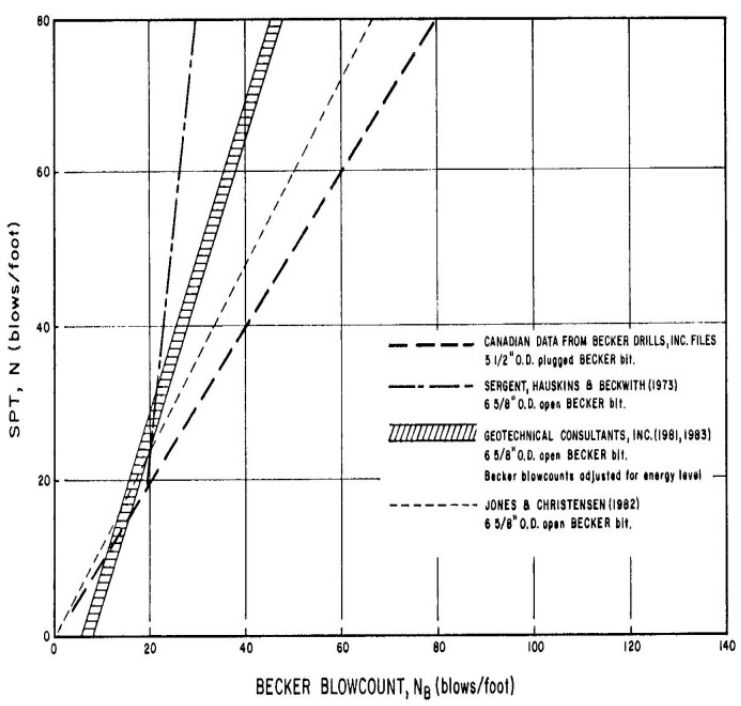

Fig. 51. Correlations between BPT and SPT values (after Harder, Seed 1986)

\section{Gravel and cobbles dimensions}

(i) Unit $a_{2}$ is composed by fine sandy materials with intercalations of silty clay material with gravel material; (ii) Unit $\mathrm{a}_{3}$ is composed by medium sandy materials with intercalations of silty clay material with gravel material with thickness varying from $3.3 \mathrm{~m}$ to $14.10 \mathrm{~m}$ and SPT values between 32 to 52 blows and penetration from 11 to $29 \mathrm{~cm}$ for 60 blows; (iii) Unit M3 is composed by sands with intercalations of gravel materials; (iv) Unit M4 is composed by sands with intercalations of gravel materials with sand silty. 


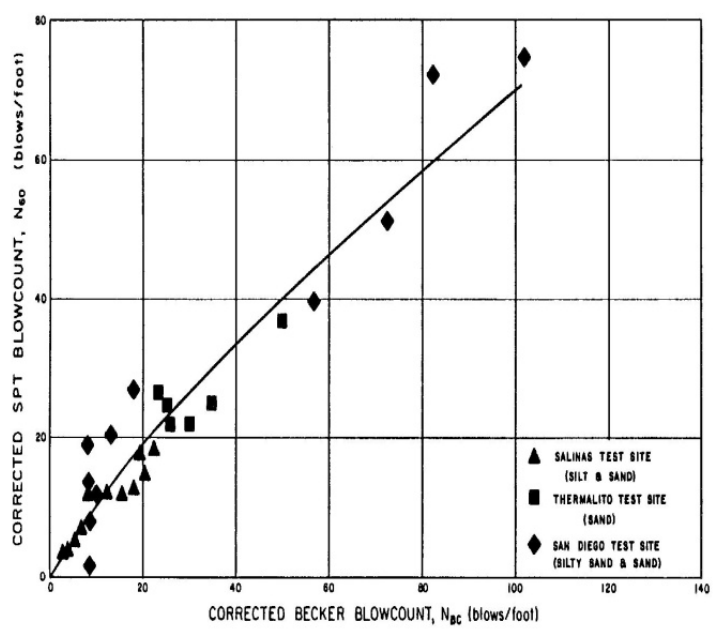

Fig. 52. Correlations between BPT and SPT modified values (after Harder, Seed 1986)

The additional geotechnical campaign has shown that for material $\mathrm{a}_{3}$ located between $\mathrm{km} 6+900-7+$ 600 and $\mathrm{km} 8+900-10+400$, the thickness was around $16 \mathrm{~m}$ and in other sites values between $(3-5 \mathrm{~m})$ and $8-12 \mathrm{~m}$ were recorded.

Within this framework it is important to analyze the dimensions of gravels and cobbles based on the referred classifications. the dimensions of gravel materials are between $4.75 \mathrm{~mm}$ and $75 \mathrm{~mm}$ following the classifications of ASTM-D2487, ASTM D6538 and USCS and from $2 \mathrm{~mm}$ to $60 \mathrm{~mm}$ following the classification of LNEC-E-219 (1968), MIT and BS 5937:1981.

ii) the cobbles have a size between $75 \mathrm{~mm}$ and 300 $\mathrm{mm}$ following the classifications proposed by USBR (1974), US Army Engineer (1960), USCS and ASTM D 653 and from $60 \mathrm{~mm}$ to $300 \mathrm{~mm}$ following the classifications of BS 5937:1981 and MIT.

In summary: Following the Geotechnical Report it was expected the occurrence of gravel materials with dimensions between of $2 \mathrm{~mm}$ and $75 \mathrm{~mm}$ and cobbles with dimensions between $60 \mathrm{~mm}$ e $300 \mathrm{~mm}$.

Unfortunately Balast Needam has not given the right attention to this issue during the metallic casings design.

\section{Final comments}

1) The recorded values of Vs for gravel materials between 320 and $400 \mathrm{~m} / \mathrm{s}$ are compatible with the existent knowledge and allow the definition of gravel compacity.

2) The recorded values of Vs and SPT values allow to classify the $\mathrm{a}_{3}$ materials as ground category B-C, following EC8.

3) The description of borehole logs of S1B and S6B in the bridge zone has allowed to characterize the thickness and compacity of the gravel materials $a_{3}$.
4) Techniques to take undisturbed samples of $a_{3}$ materials by frozen techniques were disregarded due to the high costs.

5) The SPT values of $a_{3}$ materials between $45-60$ blows are equivalent to BPT values between 60 to 80 more adequate to characterize sandy gravel materials following Harder and Seed (1986) proposal.

\section{Records of driveability of metallic casings}

The records of driveability of metallic casings have giving the following information: (i) level of penetration: (ii) number of blows to penetrate $25 \mathrm{~cm}$; (iii) energy by blow; (iv) penetration by blow; (v) time for penetration; (vi) level of top and bottom of casing; (vii) method of excavation and type of material (Ballast Nedam 2005a, 2005b, 2005c).

For Pylon P1C records of the following piles P1-1, P1-2, P1-3, P1-4, P1-5, P1-6, P1-7, P1-8, P1-9 e P1-10 were presented.

For Pylon P2C records of the following piles P2-1, P2-2, P2-3, P2-4, P2-5, P2-6, P2-7, P2-8, P2-9 e P2-10 were presented.

For Pylon P3C records of the following piles P3-5, P3-6, P3-7 e P3-8 were presented.

For Pylon $\mathrm{P} 4 \mathrm{C}$ no records were presented.

For Pylon P5C records of the following piles P5-1, P5-2, P5-3, P5-4, P5-5, P5-6, P5-7 e P5-8 were presented.

For Pylon P6C records of the following piles P6-1, P6-2, P6-3, P6-4, P6-5, P6-6, P6-7 e P6-8 were presented.

For Pylon P7C records of the following piles P7-1, P72, P7-3, P7-4, P7-5, P7-6, P7-7 e P7-8 were presented.

- Unfortunately the records presented by Ballast Nedam have not given the following information: (i) height of hammer fall; (ii) frequency; (iii) control of pile verticality; (iv) comparison between the driven logs of the casings and the borehole logs.

\section{Records of casing inspections}

The records of casings inspections have given the following information (Balast Nedam 2006):

- Design Phase: (i) length of metallic casing; (ii) level of bottom pile; (iii) penetration in Miocene.

- Execution Phase: (i) level of casing head; (ii) level of casing bottom, (iii) drivelibility of casing; (iv) depth of excavation, (v) level of pile excavation; (vi) depth of Miocene; (vii) level of embedding in the Miocene; (viii) level of pile bottom; (ix) excavation to be performed in Miocene; ( $\mathrm{x}$ ) lack of excavation missing to fulfill design requirements; (xi) description of the anomalies detected by the divers.

For pylon P1C records of piles P1-1, P1-2, P1-3, P1-4, P1-5, P1-6, P1-7, P1-8, P1-9 e P1-10, were presented. 
From the visual inspections of the metallic casings that were performed by the divers the following occurrences were recorded: (i) casings without deteriorations; (ii) light ovalization at the bottom; (iii) conic deformations at the bottom without the possibility to perform additional excavation; iv) collapse of the casing.

Generally speaking the deteriorations have occurred in an extension of 2 to $4 \mathrm{~m}$, situated at depths between $35.3 \mathrm{~m}$ and $42 \mathrm{~m}$, with the exception of casing P1-8 that have exhibited deteriorations in an extension of $16 \mathrm{~m}$, between depths of $22.5 \mathrm{~m}$ and $38.4 \mathrm{~m}$.

The type of observed deteriorations is shown in Figure 53.

The divers have considered that casings P1-1, P1-2, P1-7 e P1-9 have not exhibited deteriorations.

For pylon P2C records of piles P2-1, P2-2, P2-3, P2-4, P2-5, P2-6, P2-7, P2-8, P2-9 e P2-10 were presented.

From the visual inspections of the metallic casings that were performed by the divers the following occurrences were recorded: (i) uplift of the soil; (ii) light ovalization at the bottom; (iii) conic deformations at the bottom without the possibility to perform additional excavation; iv) collapse of the casing; (v) horizontal corrugation; vi) bended steel casing.

Generally speaking the deteriorations have occurred in an extension of 1 to $2 \mathrm{~m}$, situated at depths between $31.0 \mathrm{~m}$ and $40 \mathrm{~m}$, with the exception of casing P2-4 that has exhibited deteriorations in an extension of 8-9 m, between depths of $27.5 \mathrm{~m}$ and $36.5 \mathrm{~m}$ (TACE 2005).

For Pylon P3C records for piles P3-1, P3-2, P3-3, P3-4, P3-5, P3-6, P3-7 e P3-8 were presented.

(i) The length of excavation to respect the embedding in Miocene has varied between 0 and $0.5 \mathrm{~m}$.

\section{Monitoring during construction and long term}

\section{Introduction}

The designer has the difficult task to perform a correct definition of loads and an adequate characterization of the materials for the project. It is necessary to compare the mental model with the prototype response in order to assess the structural behavior, and to decide in face of an anomalous behavior.

Within this framework it is important to instrument the bridge with the following purposes:

i) Validation of design criteria and calibration of mental model.

ii) Analysis of bridge behavior during its life cycle.

iii) Corrective measures for the rehabilitation of the structure.

iv) Cumulative experience that will be useful for the construction of more economic and safer bridges.

\section{Quantities to be measured}

For the superstructure the measurement of the following quantities were proposed: a) deck vertical displacements; b) piers cross-sections rotations; c) internal deck and piers deformations; d) internal deck deformations due to time-dependent effects; e) deck and stays temperatures; f) air temperature, relative humidity and wind speed; g) seismic and wind induced accelerations in the deck and piers; h) forces in stays.

Related with the infrastructure the following measurements were programmed:

pile head displacements using electronic teodolytes and appropriate reflectors;
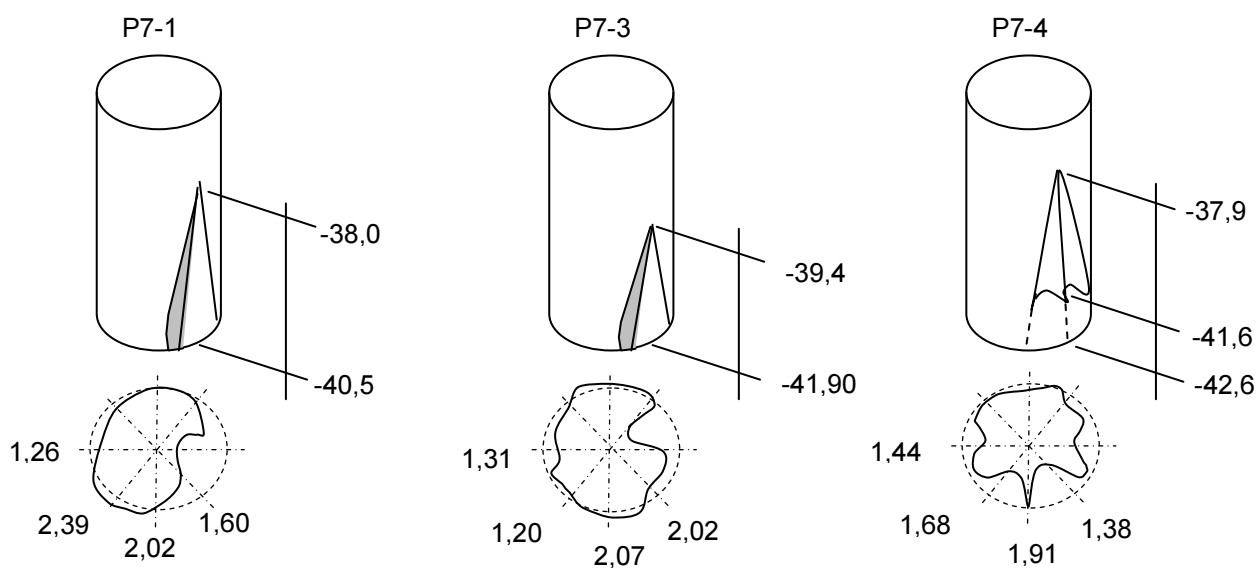

Fig. 53. Type of observed deteriorations 


\section{Warning levels}

Four warning levels were defined:

(i) warning level 1 - no interruption of traffic; (ii) warning level 2 - limitation of traffic; (iii) warning level 3 - interruption of traffic; (iv) warning level 4 decision concerning the traffic.

For warning levels 1 to 3 the maintenance team can deal with the problem alone. For warning level 4 a specialist is necessary to take the decision.

\section{Inspections}

To complement the data given by the sensors placed in different sections of the bridge regular inspections should be performed.

Four levels of inspection were proposed:

(ii) The reference situation corresponds to a detailed inspection of all parts of the structure (foundations, bearings and decks) and the measurement of all the sensors in order to characterize the initial state of the bridge before the opening to traffic;

(iii) The daily inspections aimed an efficient visual checking of the superstructure (drainage systems, road surface, expansion joints, handrail, gantries, safety barriers, lighting etc.) to detect the need of small repairs;

(iv) The annual inspections are related with the visual inspection of the foundations (measurements by sensors placed into the piles), supporting structures, bearings, expansion joints, superstructures and equipment;

(v) After the opening to traffic, the first detailed inspection will be done after two years. During the operation of the bridge the frequency is five years.

\section{Conclusions}

The following conclusions can be outlined:

1. The different geotechnical campaigns implemented during the Preliminary Study (1st phase and 2nd phase) and during the Basic Design have allowed the definition of different geological and geotechnical profiles.

2. The geotechnical characteristics were obtained after a balance between the results of the field and laboratory tests.

3. The geotechnical study in the Basic Design fulfills the requirements of Eurocode 7, Specification 1536 Bored Piles prepared by CEN - Committee TC 288 and the Procedures and Specifications for Piles prepared by ICE (1978).

4. The new Tagus Crossing is located in zone A of Portugal the highest seismic zone.

5. From the Geotechnical Report of the Basic Design the occurrence of gravel materials between 2 and $75 \mathrm{~mm}$ and cobbles materials between 60 and $300 \mathrm{~mm}$ is expected.
6. The recorded values of Vs for gravel materials between 320 and $400 \mathrm{~m} / \mathrm{s}$ are compatible with the existent knowledge and allow the definition of gravel compacity.

7. The recorded values of Vs and SPT values allow to classify the $\mathrm{a}_{3}$ materials as ground category B-C, following EC8.

8. The characterization of gravel materials due their size can not be defined adequately through SPT tests.

9. The description of borehole $\operatorname{logs}$ of S1B and $\mathrm{S} 6 \mathrm{~B}$ in the Main Bridge zone has allowed to characterize the thickness and compacity of the gravel materials $\mathrm{a}_{3}$.

10. Techniques to take undisturbed samples of $a_{3}$ materials by frozen techniques were disregarded due to the high costs.

11. The SPT values of $a_{3}$ materials between 45-60 blows are equivalent to BPT values between 60 to 80 more adequate to characterize sandy gravel materials following Harder and Seed (1986) proposal.

12. Unit $a_{3}$ is composed by medium sandy materials with intercalations of silty clay material with gravel material with thickness varying from $3.3 \mathrm{~m}$ to $14.10 \mathrm{~m}$ and SPT values between 32 to 52 blows and penetration from 11 to $29 \mathrm{~cm}$ for 60 blows.

13. The additional geotechnical campaign has shown that for material $\mathrm{a}_{3}$ located between $\mathrm{km}$ $6+900-7+600$ and $\mathrm{km} 8+900-10+400$, the thickness was around $16 \mathrm{~m}$ and in other sites values between $3-5 \mathrm{~m}$ and $8-12 \mathrm{~m}$ were recorded.

14. The piles were designed by i) design models; ii) pile load tests that have given information about the characteristics of gravel materials and techniques of driving the metallic casings; and iii) comparable experience.

15. Static pile load tests both vertical and horizontal were carried out on trial piles to calibrate the design parameters and to optimize the pile lengths. Also dynamic pile tests were performed.

16. The liquefaction potential evaluation was performed only by CPT and SPT tests due to the disturbance that occurs during sampling of sandy materials. Both total and effective stress analyses were performed.

17. Non destructive techniques of pile tests were performed to assess the quality of piles.

18. Records of casing inspections have shown the occurrences of deteriorations in an extension of 2 to $4 \mathrm{~m}$, situated at depths between 35.3 and $42 \mathrm{~m}$, with the exception of casing P1-8 that exhibited deteriorations in an extension of $16 \mathrm{~m}$, between depths of 22.5 and $38.4 \mathrm{~m}$.

19. The objectives of monitoring during construction and long term were presented. 


\section{Acknowledgments}

Due to the complexity of Leziria Tagus River Bridge several construction companies and experts were involved, namely Construction Consortium and COBA, PC\&A, CIVILSER e ARCADIS. The studies carried out by them are greatly acknowledged.

As already mentioned the field investigations were carried by Geocontrole and LNEC, and the laboratory tests were performed by Geocontrole.

Special thanks are due to TACE and particularly to Mr. Secundino Vilar and also to BRISA for the permission to publish this paper.

It is important to refer the contributions by IST for the static pile tests and also for the dynamic pile tests. Geosolve.

The reception tests for piles were carried out by

\section{References}

Ambraseys, N. N. 1998. Engineering seismology, Earthquake Engineering and Structural Dynamics 17: 1-105. http://dx.doi.org/10.1002/eqe.4290170101

ASTM D1143. Standard test method for piles under static axial compressive load. American Society for Testing Material, 1981.

ASTM D6538. Terminology relating to soil, rock, and contained fluids. American Society for Testing Material.

ASTM-D2487. Standard practice for classification of soils for engineering purposes. Annual Book of ASTM Standards. Soil and Rock; Building Stones, Geotextiles. Section 4, Vol. 04.08. American Society for Testing Material, 1987.

Ballast Nedam. 2005a. Revue proposal - Ref. 004-943ngo-7734 for the construction of piles for crossing Tagus River in Carregado.

Ballast Nedam. 2005b. Bridge over the Tagus River at Carregado working method. Excavation of 60 piles with diameter $2200 \mathrm{~mm}$ including pouring concrete. $10 \mathrm{p}$.

Ballast Nedam. 2005c. Records of driven casings for piers P1, P2, P3, P4, P5, P6 e P7. October, November (in Portuguese).

Ballast Nedam. 2006. Description of visual inspections of casings for piers of P1, P2, P3, P4, P5, P6 e P7. January (in Portuguese).

BS 5937:1981. Methods for test for soils for civil engineering purpose Part 2: Classification Tests. British Standard, 1981.

Byrne, P. M.; Beaty, M. H. 1999. Assessment residual strength for embankments, in P. S. Sêco e Pinto (Ed.). Proc. of the Second International Conference on Earthquake Geotechnical Engineering 3: 1069-1075. Published by Balkema.

Cetin, K. O.; Seed, R. B.; Kiureghion. 2001. Reliability based assessment of seismic soil liquefaction initiation, in A. Ansal (Ed.). XV ICSMGE TC4
Satellite Conference on Lessons Learned from Recent Strong Earthquakes, 25 August 2001, Istanbul, Turkey, 327-332.

COBA, PC\&A, CIVILSER e ARCADIS. 2004b. Bridge crossing Tagus River. Solution B, Vol. IIB. Basic Design of the Bridge crossing Tagus River and Access Viaducts (in Portuguese).

COBA, PC\&A, CIVILSER e ARCADIS. 2004a. North viaduct, Vol. 1. Basic Design of the Bridge crossing Tagus River and Access Viaducts (in Portuguese).

COBA, PC\&A, CIVILSER e ARCADIS. 2004c. Geological and geotechnical study - part $1 a-$ description of the solution, Vol. IV. Basic Design of the Bridge crossing Tagus River and Access Viaducts (in Portuguese).

COBA, PC\&A, CIVILSER e ARCADIS. 2004d. Geological and geotechnical study - part $2 b-$ additional geotechnical programme, Vol. IV. Basic Design of the Bridge crossing Tagus River and Access Viaducts (in Portuguese).

COBA, PC\&A, CIVILSER e ARCADIS. 2004e. Geological and Geotechnical Study - Part 3C List of Drawings, Vol. IV. Basic Design of the Bridge crossing Tagus River and Access Viaducts (in Portuguese).

COBA, PC\&A, CIVILSER e ARCADIS. 2005a. Methodology for static pile tests. Technical Note no 3. Revision 4, May (in Portuguese).

COBA, PC\&A, CIVILSER e ARCADIS. 2005b. Memochange of place for static horizontal tests. June (in Portuguese).

COBA, PC\&A, CIVILSER e ARCADIS. 2005c. Revision of pile design. Technical Note no. 38 . September (in Portuguese).

COBA, PC\&A, CIVILSER e ARCADIS. 2005d. Bridge crossing Tagus River, Vol. II. Basic Design of the Bridge crossing Tagus River and Access Viaducts. October (in Portuguese).

COBA, PC\&A, CIVILSER e ARCADIS. 2005e. Geological and geotechnical study - description of the solution, Vol. IV. Final Design of the Bridge crossing Tagus River and Access Viaducts, October (in Portuguese).

COBA, PC\&A, CIVILSER e ARCADIS. 2005f. Anexes "Geological and geotechnical study - description of the solution", Vol. IV B. Final Design of the Bridge crossing Tagus River and Access Viaducts, October (in Portuguese).

COBA, PC\&A, CIVILSER e ARCADIS. 2005g. Geological and geotechnical study - part 3c-list of drawings, Vol. IV. Final Design of the Bridge crossing Tagus River and Access Viaducts, October (in Portuguese).

COBA, PC\&A, CIVILSER e ARCADIS. 2005h. Constructive procedures, Vol. IX. Final Design of the Bridge crossing Tagus River and Access Viaducts (in Portuguese). 
Daniel, C. R.; Howie, J. A.; Campanella, R. G. 2004. Characterization of SPT grain size effects in gravels, in Proc. ISC 2, Geotechnical and Geophysical Site Characterization, 19-22 September 2004, Porto, Portugal, 1: 299-306.

Eurocode 7. Geotechnical design. Part 1. Brussels, 1997.

Eurocode 8. Design of structures for earthquake resistance. Brussels, 1998a.

Eurocode 8. Design provisions for earthquake resistance of structures - part 5. Foundations, retaining structures and getechnical aspects. Brussels, 1998b.

Ferreira, S.; Rebelo, V.; Ribeiro, J. 2008. Pile foundations for Leziria Bridge. $11 \mathrm{CNG}$, Coimbra (in Portuguese).

GEOCISA. 2003. A-10 - New Tagus crossing - downhole and cross-hole tests. November (in Portuguese).

Geocontrole. 2004a. A10 - Tagus crossing in Carregado. Basis design. Geotechnical campaign. Study for the Construction Consortium MSF, BPC, ZAGOPE, Construtora do Tâmega and Construtora do Lena, February (in Portuguese).

Geocontrole. 2004b. A10 - Tagus crossing in Carregado. Complementary geotechnical campaign, Vol. I: Memory (in Portuguese).

Geocontrole. 2004c. A10 - Tagus crossing in Carregado. Complementary geotechnical campaign, Vol. II: Laboratory tests (in Portuguese).

GEOSOLVE. 2005a. Verification of pile integrity by cross hole tests. Pile experimental site KM $8+$ 200. Report no 1 (in Portuguese).

GEOSOLVE. 2005b. Verification of pile integrity by cross hole tests. Pile experimental site KM $5+$ 400, KM $7+900, K M 8+200$. Report no 2 (in Portuguese).

GEOSOLVE. 2005c. Verification of pile integrity by cross hole tests. Pile Experimental Site KM $5+$ 400. Report no 3 (in Portuguese).

GRID. 2003. Crossing of Tagus River in Carregado. Preliminar study. Description of the solution. Highway A10 /Carregado/IC3. Sublanço A1/Benavente. November (in Portuguese).

Harder, L.; Seed, H. B. 1986. Determination of penetrometer resistance for Coarse Gravel Soils using the Becker Hammer Dril. UCB/EERC 86/061.

ICE. 1978. Piling - model procedures and specifications. Institution of Civil Engineers, London.

ICIST-IST. 2005. Experimental pile load tests. Report. New Tagus River Crossing at Carregado, August.

Imai, T. 1977. $P$ and $S$ wave velocities of the ground in Japan, in Proceedings of the $9^{\text {th }}$ International Conference Soil Mechanics and Foundation Engineering, 1977, Tokyo, Japan.
INA. 2001. Seismic design guidelines for port structures. International Navigation Association. A. A. Balkema Publishers.

Ishihara, K. 1993. Liquefaction and flow failure during earthquakes, $33^{\text {rd }}$ Rankine Lecture, Geotechnique 43(3): 351-415. http://dx.doi.org/10.1680/geot.1993.43.3.351

Ishihara, K.; Yasudfa, S.; Yoshida, Y. 1990. Liquefaction induced flow failure of embankments and residual strength of silty sands, Soils and Foundations 30(3): 69-80. http://dx.doi.org/10.3208/sandf1972.30.3_69

ISSMFE. 1981. Vocabulary - definitions and symbols. International Society for Soil Mechanics and Geotechnical Engineering.

IST. 2004a. Generation of response and displacements spectra of alluvial soils of Carregado Site, February.

IST. 2004b. Dynamic characterization of alluvial soils at Carregado Site, December. (in Portuguese).

IST. 2005. Dynamic characterization of alluvial soils at Carregado Site, May (in Portuguese).

Jeremias, F. T.; Coelho, A. G.; Sardinha, R. 2007. Liquefaction potential evaluation of alluvial materials at new crossing of Tagus River in Carregado, in $7^{\text {th }}$ Portuguese Congress on Seismology and Earthquake Engineering (in Portuguese).

LNEC. 2003. A-10 - New Tagus Crossing - cross-hole tests (in Portuguese).

LNEC-E-219. 1968. Ground geotechnical investigation (in Portuguese).

NCEER. 1997. Proc. NCCER workshop on evaluation of liquefaction resistance of soils, summary report, Technical Report NCEER-97-0022. T. L. Youd, I. M. Idriss (Eds.). National Center for Earthquake Engineering Research, University of Buffalo.

Oliveira, R.; Rebelo, V.; Jeremias, F.; Coelho, A. G.; Sardinha, R. 2008. Geological and geotechnical studies fo the basic design of a new bridge over the Tagus River, at Carregado. $11 \mathrm{CNG}$, Coimbra (in Portuguese).

Portugal, A.; Perry da Câmara, A.; Virtuoso, F.; Rebelo, V. 2005. New crossing across Tagus River in Carregado. JPEE, Lisboa (in Portuguese).

Rodrigues, L. F. 1979. Methods for seismic site investigation in engineering geology. The importance of shear wave: Research thesis. LNEC (in Portuguese).

RSA. 1983. Portuguese safety and actions code for buildings and bridges (in Portuguese).

Sêco e Pinto, P. S.; Oliveira, R. 1998. A Recent Difficult Foundation Problem: The Case of the New Tagus Bridge, in $4^{\text {th }}$ International Conference on Case Histories in Geotechnical Engineering, 912 March 1998, St. Louis, USA. 
Sêco e Pinto, P. S.; Correia, J.; Vieira, A. 1997. Evaluation of liquefaction potential of a site located in the South of Portugal, in P. S. Sêco e Pinto (Ed.). Proc. of the Discussion Special Technical Session on Earthquake Geotechnical Engineering during $14^{\text {th }}$ ICSMFE, 1997, Hamburg, Germany, 113-124. Published by Balkema.

Sêco e Pinto, P. S.; Rodrigues, L. F. 1989. Pile integrity tests in Boinas Bridge, in $3^{\text {rd }}$ Portuguese Geotechnical Congress, 1989, Porto, Portugal (in Portuguese).

Seed, H. B.; Harder, L. F. 1990. SPT-based analysis of cyclic pore pressure generation and undrained residual strength, in Proc. of Memorial Symposium of H. B. Seed, 2: 351-376.

Seed, H. B.; Idriss, I. M. 1982. Ground motions and soil liquefaction during earthquakes. Earthquake Engineering Research Institute, Oakland, California.

Seed, R. B.; Cetin, K. O.; Moss, R. E. S. 2001. Recent advances in soil liquefaction hazard assessment, in A. Ansal (Ed.). XV ICSMGE TC4 Satellite Conference on Lessons Learned from Recent Strong Earthquakes, 2001, Istanbul, Turkey, 319 326.

Stokoe, K. H. II.; Darendeli, M. B.; Andrus, R. D.; Brown, L. T. 1999. Dynamic soil properties: Laboratory, field and correlation studies. Theme Lecture, in P. Sêco e Pinto (Ed.). Proc. of $2^{\text {nd }}$ International Conference on Earthquake Geotechnical Engineering, 1999, Lisboa, Portugal, 3: 811-845. Published by A. Balkema.
TACE. 2005. Report of Experimental Pile Construction for Tests by Eng ${ }^{\circ}$ Secundino Vilar, Technical Note 30. October (in Portuguese).

TC4 ISSMGE. 2001. Case Histories of PostLiquefaction Remediation. Committee on Earthquake Geotechnical Engineering.

Tokimatsu, K.; Kuwayama, S.; Tamura, S. 1991. Liquefaction potential evaluation based on Rayleigh wave investigation and its comparison with field behavior, in Proceedings $2^{\text {nd }}$ Int. Conf. on Recent Advances in Geotech. Earthquake Eng. And Soil Dynamics, 11-15 March 1991, St. Louis, 1: 357-364. http://dx.doi.org/10.1061/(ASCE) 0733-9410(1987)113:8(861)

Tokimatsu, K.; Seed, H. B. 1987. Evaluation of settlements in sands due to earthquake shaking, Journal of Geotechnical Engineering ASCE 113: 861-878.

USBR. 1974. Earth manual. United States Bureau of Reclamation.

Youd, T. L.; Gilstrap, S. D. 1999. Liquefaction and deformation of silty and fine-grained soils. General Report, in P. Sêco e Pinto (Ed.). Proc. of $2^{\text {nd }}$ International Conference on Earthquake Geotechnical Engineering, 1999, Lisboa, Portugal, 3: 1013-1020. Published by A. Balkema. 